\title{
A Real-Time PCR Differentiating Pantoea stewartii subsp. stewartii From $P$. stewartii subsp. indologenes in Corn Seed
}

\author{
Narinder Pal, ${ }^{1}$ Charles C. Block, ${ }^{2, \dagger}$ and Candice A. C. Gardner ${ }^{1}$ \\ ${ }^{1}$ U.S. Department of Agriculture-Agricultural Research Service North Central Regional Plant Introduction Station, \\ Ames, IA 50011 \\ ${ }^{2}$ Seed Science Center, Iowa State University, Ames, IA 50011
}

\begin{abstract}
Stewart's wilt of corn caused by the bacterium Pantoea stewartii subsp. stewartii is a seed-borne disease of major phytosanitary importance. Many countries have imposed restrictions on corn seed imports from regions where the disease occurs to prevent the potential introduction of the pathogen. Current laboratory testing methods (enzyme-linked immunosorbent assay [ELISA] and polymerase chain reaction [PCR]) cannot readily distinguish $P$. stewartii subsp. stewartii from the closely related subspecies Pantoea stewartii subsp. indologenes. However, P. stewartii subsp. indologenes, a nonpathogen on corn, is occasionally found on corn seed as part of the resident bacterial population and can yield false positive test results. A real-time PCR targeting the $\operatorname{cps} A B$ intergenic

sequence was developed to specifically detect $P$. stewartii subsp. stewartii from corn seeds and distinguish it from $P$. stewartii subsp. indologenes. The assay successfully detected $P$. stewartii subsp. stewartii from corn seed, and $P$. stewartii subsp. indologenes-contaminated seed lots, which previously yielded false positives by ELISA and published PCR methods, were negative. The absence of $P$. stewartii subsp. stewartii and the presence of $P$. stewartii subsp. indologenes in this seed were confirmed by size differentiation of the $\operatorname{cps} A B$ amplicons in a conventional PCR. By distinguishing the two subspecies, the assays described would avoid false positive results and help prevent unnecessary restrictions on international movement of corn seed.
\end{abstract}

Pantoea stewartii subsp. stewartii (Smith 1898) Mergaert et al. 1993 (syn. Erwinia stewartii [Smith 1898] Dye 1963) (Dye 1963; Mergaert et al. 1993) is the causal agent of Stewart's wilt, also called Stewart's disease or Stewart's bacterial wilt of corn. The main hosts for the bacterium include flint corn, sweet corn, yellow dent (field) corn, popcorn, teosinte, and eastern gamagrass. There are two phases describing symptoms of Stewart's wilt: the wilt phase and the leaf blight phase. The wilt phase occurs when highly susceptible plants become systemically infected during early vegetative growth. The host plant's xylem tissue is colonized by bacterial cells, which produce an extracellular polysaccharide (EPS) called stewartan that plugs the xylem vessels and causes wilting. Infected seedlings may die prematurely. Plants that are not killed may remain stunted and produce bleached dead tassels. Dent (field) corn is generally less susceptible than sweet corn to the wilt phase, and although some inbred lines are susceptible, dent corn hybrids are usually resistant. Significant losses in yield from susceptible and moderately susceptible sweet corn hybrids have been reported (Suparyono and Pataky 1989). The leaf blight phase of the disease is more common but less damaging than the wilt phase. It can occur at any growth stage and is generally associated with local infection of the leaf tissue via feeding by the corn flea beetle vector Chaetocnema pulicaria Melsheimer. Symptoms develop as graygreen to yellow-green streaks with wavy margins along the veins,

${ }^{\dagger}$ Corresponding author: C. C. Block; ccblock@iastate.edu

Funding: This research was supported by the U.S. Department of AgricultureAgricultural Research Service North Central Regional Plant Introduction Station.

*The $\boldsymbol{e}$-Xtra logo stands for "electronic extra" and indicates that one supplementary figure and one supplementary table are published online.

The author(s) declare no conflict of interest.

Accepted for publication 15 January 2019.

This article is in the public domain and not copyrightable. It may be freely reprinted with customary crediting of the source. The American Phytopathological Society, 2019 and they are most noticeable after tasseling. The streaked areas eventually turn necrotic and straw colored. If the disease is severe, entire leaves may die prematurely, and it also predisposes the plant to fungal stalk rots (Jardine and Claflin 2016).

The corn flea beetle is the primary vector of the bacterium (Elliott and Poos 1934, 1940). Adult beetles harbor the bacteria in their gut, emerge in the spring about the time that corn is planted, and disseminate the bacteria throughout the corn-growing season. The bacterium enters the plant through feeding wounds and colonizes intercellular spaces of leaf tissue as well as xylem, thereby causing characteristic water-soaked lesions and wilting. Plant-to-plant spread does not occur without the presence of corn flea beetle feeding, and disease incidence is directly related to the size of flea beetle population (Cook et al. 2005). Some grassy weeds have been shown to be symptomless carriers of the bacterium, but their role as overwintering hosts is not well known (Jardine and Claflin 2016).

P. stewartii subsp. stewartii is indigenous to North America, having first been reported on Long Island in New York State in 1897 (Stewart 1897). The disease has occasionally been reported in other parts of the world (Canada, Mexico, Austria, Argentina, Bolivia, Italy, Poland, Romania, Russia, China, Korea, Malaysia, Thailand, and Vietnam) (CABI 2018), but the pathogen is not well established in these areas, probably because of the absence of a suitable insect vector. The economic importance of the disease in North America has declined since the 1930s with the introduction of more resistant hybrids and the common use of systemic seed-applied insecticides. Seed transmission is rare, and the likelihood of seed transmission is low from commercial seed lots; however, the risk is still more than zero if infected seeds are present. Block et al. (1998) reported a seed transmission rate of $0.022 \%$ from naturally infected seeds (one infected plant from 4,563 infected kernels), and Michener et al. (2002) reported a similar seed transmission rate of $0.038 \%$ (22 infected plants from 58,300 infected kernels). However, Stewart's wilt is still a major issue when seed is destined for export; $>100$ countries impose phytosanitary restrictions on importation of corn seed and require phytosanitary certification that the shipment is free of $P$. stewartii. These phytosanitary restrictions have a large impact on the corn seed industry and seed trade in terms of seed health testing costs and potential loss of export markets. Hence, quick and accurate detection of $P$. stewartii subsp. stewartii is very important. 
Many testing methods have been developed for the detection of $P$. stewartii in pure cultures, infected corn leaf tissue, or seeds (Blakemore et al. 1999; Coplin et al. 2002; Gehring et al. 2014; Lamka et al. 1991; Nechwatal et al. 2018; Tambong 2015; Tambong et al. 2008; Thapa et al. 2012; Uematsu et al. 2015; Wensing et al. 2010; Wilson et al. 1994; Wu et al. 2007; Xu et al. 2010). Enzyme-linked immunosorbent assay (ELISA), a serological method (Lamka et al. 1991) based on polyclonal capture and monoclonal detection antibodies, is widely used in the United States for commercial seed certification. Block et al. (2011) found that ELISA and nine published polymerase chain reaction (PCR) methods were prone to occasional false positive cross-reactions with, at the time, unidentified Pantoea isolates from tropical or subtropical corn seed. The unknowns were later identified by multilocus sequencing as Pantoea stewartii subsp. indologenes Mergaert et al. 1993, first described by Mergaert et al. (1993). P. stewartii subsp. indologenes can cause leaf spots on foxtail millet (Setaria italica) and pearl millet (Pennisetum americanum), rot of pineapple (Ananas comosus), and center rot of onion (Stumpf et al. 2018); however, it is avirulent on corn, and it is not a regulated corn pest in any country. P. stewartii subsp. indologenes is occasionally present on corn seed of tropical or subtropical origin as part of resident bacterial population (Block et al. 2011; Gehring et al. 2014; Nechwatal et al. 2018; Tambong 2015).

Thapa et al. (2012) developed a multiplex PCR for P. stewartii subsp. stewartii with three primer pairs targeting three different genes, wtsE (water-soaking), cpsA (EPS production) and $h r p N$ genes (hypersensitive response in nonhost), and each primer pair was reported as being specific to $P$. stewartii subsp. stewartii. Nechwatal et al. (2018), in a PCR validation study, showed evidence of crossreactivity with $P$. stewartii subsp. indologenes using the primers of Thapa et al. (2012) and also stated that the recommended EPPO Diagnostic Protocol PM 7/60 (EPPO 2016) was prone to false positives. Nechwatal et al. (2018) evaluated several primer sets and concluded that the galE primers of Gehring et al. (2014) were capable of differentiating the two subspecies based on single-nucleotide polymorphisms (SNPs). The SNPs are present as the last base at the $3^{\prime}$ end of the forward and reverse primers. The galE primers were validated with three $P$. stewartii subsp. indologenes isolates from corn and seven isolates from other plant hosts plus a small number of corn seed samples (Gehring et al. 2014; Nechwatal et al. 2018). Although promising, the SNP primers would benefit from testing additional $P$. stewartii subsp. indologenes isolates, especially from corn. Little is known about variability in $P$. stewartii subsp. indologenes isolates and the risks associated with reliance on single-base pair differences for identification.

The objectives of this study were to (1) develop a convenient, reliable real-time PCR assay for specific detection of $P$. stewartii subsp. stewartii from corn seeds without the need for bacterial isolation, biochemical characterization of isolates (e.g., indole and esculin), and additional PCR tests to confirm bacterial identity and (2) clearly distinguish $P$. stewartii subsp. stewartii from $P$. stewartii subsp. indologenes.

\section{Materials and Methods}

Bacterial strains. All bacterial strains (Table 1) were cultured on Luria-Bertani (tryptone, $1 \%$; yeast extract, $0.5 \%$; NaCl, $1 \%$; and agar, $1.5 \%$ ) or nutrient broth yeast extract agar (nutrient broth, $0.8 \%$; yeast extract, $0.2 \% ; \mathrm{K}_{2} \mathrm{HPO}_{4}, 0.2 \% ; \mathrm{KH}_{2} \mathrm{PO}_{4}, 0.05 \%$; dextrose, $0.5 \% ; \mathrm{MgSO}_{4} 0.7 \mathrm{H}_{2} \mathrm{O}, 0.025 \%$; and agar, $1.5 \%$ ) at $28^{\circ} \mathrm{C}$ for 1 to 3 days. Sixty-seven Pantoea isolates that included $26 P$. stewartii subsp. stewartii, 17 P. stewartii subsp. indologenes, 11 Pantoea agglomerans, and 13 Pantoea ananatis from multiple hosts plus 7 non-Pantoea isolates were tested by ELISA and six conventional and three real-time PCR methods, and they were characterized by various physiological, biochemical, and pathogenicity tests (Table 1). Physiological and biochemical characteristics included gram staining (KOH test), motility test, Hugh-Leifson oxidation/ fermentation test, indole production, and esculin hydrolysis. Genomic DNA was extracted by using the Wizard Genomic DNA purification kit (Promega) and quantified using a NanoDrop ND1000 spectrophotometer (NanoDrop Technologies). Corn seeds of the accessions (entries with Ames, NSL, or PI numbers) listed in Tables 2 and 3 were acquired from the U.S. National Plant Germplasm System collection in Ames, Iowa.

ELISA. ELISA tests of bacterial cultures and corn seeds were performed according to the manufacturer's instructions for the P. stewartii reagent set (Agdia Inc.).

Pathogenicity test on corn seedlings. Ten-day-old corn inbred Mt42 seedlings were inoculated by stem injection with the respective bacterial cultures (Table 1) under greenhouse conditions $\left(28^{\circ} \mathrm{C}\right.$ day/ $24^{\circ} \mathrm{C}$ night). One milliliter of inoculum $\left(\sim 10^{8} \mathrm{CFU} / \mathrm{ml}\right)$ in $1 \times$ phosphate buffered saline (PBS), $\mathrm{pH} 7.4$, containing $0.02 \%$ Tween-20 was injected into stems near the base of leaf whorl with a 26-gauge tuberculin syringe, and seedlings were evaluated for symptoms 8 to 10 days after inoculation. Control seedlings were inoculated with buffer alone.

Comparison of bacterial extraction procedures from seed. Two buffers, $1 \times$ PBS, pH 7.4, and $0.85 \%$ normal saline with $0.02 \%$ Tween-20, were compared with sterile milliQ water for their efficiency in extracting the target ( $P$. stewartii subsp. stewartii) bacteria from corn seeds (Table 4). Three seed lots were tested: (1) LN1 with $3.5 \%$ infected seeds (seed infection percentage determined by single-seed ELISA), (2) AN1 with 9\% infected seeds (both from naturally infected inbred A632Ht), and (3) AR4 with $37 \%$ infected seeds harvested from an inoculated corn inbred A632Ht (Block et al. 1998). Fifty whole corn seeds from each of the three lots were incubated in $50 \mathrm{ml}$ of $1 \times \mathrm{PBS}$ buffer, $50 \mathrm{ml}$ of saline solution, or $50 \mathrm{ml}$ of milliQ water at room temperature on a shaker at $160 \mathrm{rpm}$ for $4 \mathrm{~h}$. Seed washes were processed as described below in the section on SYBR Green real-time PCR. The experiment was repeated twice with three replicate samples per run.

To compare the sensitivity of detection using whole seed versus ground seed, ground seed mixtures from 50 seeds per lot were incubated with either sterile PBS or sterile water at room temperature for $30 \mathrm{~min}$ with occasional mixing. A 1.2-ml aliquot was centrifuged at 1,000 relative centrifugal force (RCF) for $5 \mathrm{~min}$ to pellet corn debris, and the supernatant was transferred to a new tube; $2 \mu l$ of the supernatant was used directly for real-time PCR after an initial denaturation at $95^{\circ} \mathrm{C}$ for $10 \mathrm{~min}$.

Primer design. Primers were designed from the intergenic DNA sequence present between the $\operatorname{cps} A$ and $\operatorname{cps} B$ genes of the wce-I operon. The wce-I operon consists of 12 genes, and it is the primary stewartan EPS biosynthesis cluster (Coplin and Majerczak 1990; Wang 2011). The cpsA gene codes for WceG, a glycosyltransferase protein, and the cps $B$ gene codes for Wza, a periplasmic protein involved in export of EPS. A previous study by Thapa et al. (2012) described primers cpsF (5'-AAGGTGCCAGCCTCTCTCTG-3') and cpsR (5'- ACTATCCTGACTCAGGCACT-3') (Fig. 1) as being designed from the cpsA gene and highly selective for $P$. stewartii subsp. stewartii. However, in this study, a Clustal Omega alignment of the intergenic sequence between the cpsA and $\operatorname{cps} B$ genes of $P$. stewartii subsp. stewartii reference strain DC283 (GenBank accession number $\mathrm{CP} 017581$ ) and $P$. stewartii subsp. indologenes strain LMG2632 (GenBank accession number JPKO01000031) revealed a 182-bp deletion in $P$. stewartii subsp. indologenes strain LMG2632 (Fig. 1). The alignment of the cpsAB intergenic region (Fig. 1) showed that the cpsF and cpsR primer binding sites were actually present in both $P$. stewartii subspecies, which suggested that two different-sized amplicons should be generated: $375 \mathrm{bp}$ for $P$. stewartii subsp. stewartii and 193 bp for $P$. stewartii subsp. indologenes. Thapa et al. (2012) reported no amplification using cpsF/cpsR from either of two $P$. stewartii subsp. indologenes isolates tested (ATCC 35396 and ATCC 51785).

The deleted region in $P$. stewartii subsp. indologenes was targeted in this study for the design of a unique $P$. stewartii subsp. stewartiispecific forward primer named cpsAB2313F (5'-AGAAAACGCT GATGCCAGAC-3') (Fig. 1). When combined with reverse primer cpsR, the expected product is a 256-bp amplicon from $P$. stewartii subsp. stewartii DNA and no amplicon from $P$. stewartii subsp. indologenes DNA. 
Table 1. Pathogenicity, polymerase chain reaction (PCR), and biochemical reactions of bacterial strains used in this study ${ }^{\mathrm{a}}$

\begin{tabular}{|c|c|c|c|c|c|c|c|c|c|c|c|c|c|c|}
\hline \multirow[b]{2}{*}{ Bacterial strain } & \multirow[b]{2}{*}{ Origin (source if known) } & \multirow{2}{*}{$\begin{array}{c}\text { Pathogenicity } \\
\text { in maize }\end{array}$} & \multirow{2}{*}{$\begin{array}{c}\text { SW } \\
\text { ELISA }\end{array}$} & \multicolumn{9}{|c|}{$\begin{array}{c}\text { Conventional and real-time PCR methods } \\
\text { (method I is the real-time PCR assay } \\
\text { developed in this study) }\end{array}$} & \multicolumn{2}{|c|}{$\begin{array}{l}\text { Biochemical } \\
\text { tests }\end{array}$} \\
\hline & & & & $\mathbf{A}^{\mathbf{b}}$ & $\mathbf{B}^{\mathbf{c}}$ & $\mathbf{C}^{\mathbf{d}}$ & $\mathbf{D}^{\mathbf{e}}$ & $\mathbf{E}^{\mathbf{f}}$ & $\mathbf{F}^{\mathrm{g}}$ & $\mathbf{G}^{\mathbf{h}}$ & $\mathbf{H}^{\mathbf{i}}$ & $\mathbf{I}^{\mathbf{j}}$ & Esculin & Indole \\
\hline \multicolumn{15}{|c|}{$\begin{array}{l}\text { Pantoea stewartii subsp. } \\
\text { stewartii strains }\end{array}$} \\
\hline DC283 & $\begin{array}{l}\text { Nal mutant of SS104 } \\
\text { (D. Coplin) }\end{array}$ & + & + & + & + & + & + & + & + & + & + & + & - & - \\
\hline ES0601 & $\begin{array}{l}\text { Coix lacryma-jobi, IA, } 2006 \\
\text { (C. Block) }\end{array}$ & + & + & + & + & + & + & + & + & + & + & + & - & - \\
\hline ES9211 & Corn, IA, 1992 (C. Block) & + & + & + & + & + & + & + & + & + & + & + & - & - \\
\hline ES9230 & Corn, IA, 1992 (C. Block) & + & + & + & + & + & + & + & + & + & + & + & - & - \\
\hline ES9239 & Corn, IA, 1992 (C. Block) & + & + & + & + & + & + & + & + & + & + & + & - & - \\
\hline ES9245 & Corn, IA, 1992 (C. Block) & + & + & + & + & + & + & + & + & + & + & + & - & - \\
\hline GAL-E8 & Avirulent mutant (D. Coplin) & - & + & + & + & + & + & + & + & + & + & + & - & - \\
\hline MU51 & Avirulent mutant (D. Coplin) & - & + & + & + & + & + & + & + & + & + & + & - & - \\
\hline SS104 & Corn, IL, 1967 (D. Coplin) & + & + & + & + & + & + & + & + & + & + & + & - & - \\
\hline SW1 & Corn, OH, 1974 (D. Coplin) & + & + & + & + & + & + & + & + & + & + & + & - & - \\
\hline SW2 & Corn, OH, 1974 (D. Coplin) & + & + & + & + & + & + & + & + & + & + & + & - & - \\
\hline SW13 & Corn, IN, 1975 (D. Coplin) & + & + & + & + & + & + & + & + & + & + & + & - & - \\
\hline SW14 & Corn, IN, 1975 (D. Coplin) & + & + & + & + & + & + & + & + & + & + & + & - & - \\
\hline SW19 & Corn, KY, 1975 (D. Coplin) & + & + & + & + & + & + & + & + & + & + & + & - & - \\
\hline SW36 & Corn, TN, 1975 (D. Coplin) & + & + & + & + & + & + & + & + & + & + & + & - & - \\
\hline SW39 & Corn, NC, 1975 (D. Coplin) & + & + & + & + & + & + & + & + & + & + & + & - & - \\
\hline SW45 & Corn, MO, 1975 (D. Coplin) & + & + & + & + & + & + & + & + & + & + & + & - & - \\
\hline SW87-2 & Corn, IA, 1987 (G. Lamka) & + & + & + & + & + & + & + & + & + & + & + & - & - \\
\hline SW87-5 & Corn, IA, 1987 (G. Lamka) & + & + & + & + & + & + & + & + & + & + & + & - & - \\
\hline SW87-8 & Corn, IA, 1987 (G. Lamka) & + & + & + & + & + & + & + & + & + & + & + & - & - \\
\hline SW87-10 & Corn, IA, 1987 (G. Lamka) & + & + & + & + & + & + & + & + & + & + & + & - & - \\
\hline SW87-11 & Corn, IA, 1987 (G. Lamka) & + & + & + & + & + & + & + & + & + & + & + & - & - \\
\hline SSB30 & Corn, IA, 1992 (C. Block) & + & + & + & + & + & + & + & + & + & + & + & - & - \\
\hline ATCC-8199 & Sweet corn IA (E. Lindstrom) & + & + & + & + & + & + & + & + & NT & NT & + & - & - \\
\hline ATCC-29231 & Insect, CT (D. Sands) & + & + & + & + & + & + & + & + & + & NT & + & - & - \\
\hline NRRL B-195 & Corn, WI (A. Riker) & + & + & + & + & + & + & + & + & + & + & + & - & - \\
\hline \multicolumn{15}{|c|}{$\begin{array}{l}\text { Pantoea stewartii subsp. } \\
\text { indologenes strains }\end{array}$} \\
\hline 0696-16 & $\begin{array}{l}\text { Sudangrass, CA, } 1996 \\
\text { (H. Azad) }\end{array}$ & - & - & + & + & $+^{\mathrm{k}}$ & $+^{\mathrm{k}}$ & + & + & + & + & - & + & - \\
\hline 0696-18 & $\begin{array}{l}\text { Sudangrass, CA, } 1996 \\
\text { (H. Azad) }\end{array}$ & - & - & + & + & + & - & + & + & + & + & - & + & + \\
\hline 0696-19 & Sudangrass, CA, 1996 (H. Azad) & - & - & + & + & + & - & + & + & + & + & - & + & + \\
\hline $0696-21$ & $\begin{array}{l}\text { Sudangrass, CA, } 1996 \\
\quad(\text { H. Azad) }\end{array}$ & - & - & + & + & + & - & + & + & + & + & - & + & + \\
\hline NRRL B-1061 & Sugarcane, FL (B. Bourne) & - & - & $t^{\mathrm{k}}$ & $+^{\mathrm{k}}$ & $t^{\mathrm{k}}$ & + & + & + & + & + & - & + & + \\
\hline ATCC-35397 & Melon, Venezuela (J. Wells) & - & - & $+^{\mathrm{k}}$ & $+^{\mathrm{k}}$ & $+^{\mathrm{k}}$ & + & + & + & + & + & - & + & + \\
\hline ATCC-51785 & Setaria spp., India & - & - & $+^{\mathrm{k}}$ & $+^{\mathrm{k}}$ & $+^{\mathrm{k}}$ & + & + & + & + & + & - & + & + \\
\hline $645-3$ & $\begin{array}{l}\text { Corn seed, P. Rico, } 2010 \\
\text { (C. Block) }\end{array}$ & - & + & + & + & $+^{\mathrm{k}}$ & $+^{\mathrm{k}}$ & + & + & $+^{\mathrm{k}}$ & + & - & + & + \\
\hline $645-10$ & $\begin{array}{l}\text { Corn seed, P. Rico, } 2010 \\
\text { (C. Block) }\end{array}$ & - & + & + & + & $+^{\mathrm{k}}$ & $+^{\mathrm{k}}$ & + & + & $+^{\mathrm{k}}$ & + & - & + & + \\
\hline $645-14$ & $\begin{array}{l}\text { Corn seed, P. Rico, } 2010 \\
\text { (C. Block) }\end{array}$ & - & + & + & - & $+^{\mathrm{k}}$ & $+^{\mathrm{k}}$ & + & + & $+^{\mathrm{k}}$ & + & - & + & + \\
\hline $649-2$ & $\begin{array}{l}\text { Corn seed, P. Rico, } 2010 \\
\text { (C. Block) }\end{array}$ & - & + & + & + & + & $+^{\mathrm{k}}$ & + & + & + & + & - & + & + \\
\hline $651-3$ & $\begin{array}{l}\text { Corn seed, P. Rico, } 2010 \\
\text { (C. Block) }\end{array}$ & - & - & + & + & $+^{\mathrm{k}}$ & $+^{\mathrm{k}}$ & + & + & + & + & - & + & + \\
\hline \multirow[t]{2}{*}{$655-2 B-Y 1$} & $\begin{array}{l}\text { Corn seed, P. Rico, } 2010 \\
\text { (C. Block) }\end{array}$ & - & + & + & + & $+^{\mathrm{k}}$ & + & + & + & + & + & - & + & + \\
\hline & & & & & & & & & & & \multicolumn{4}{|c|}{ (Continued on next page) } \\
\hline
\end{tabular}

a ELISA, enzyme-linked immunosorbent assay; NT, not tested; Pseud. syr., Pseudomonas syringae; P. Rico, Puerto Rico; Sorg., sorghum; SW, Stewart's wilt; Xant., Xanthomonas; ISU, Iowa State University; +, positive; -, negative; +/-, ambiguous results.

b Conventional PCR using CPSL1 and CPSR2c primer set (Coplin et al. 2002).

c Conventional PCR using HRP1d and HRP3c primer set (Coplin et al. 2002).

${ }^{\mathrm{d}}$ Conventional PCR using ESI6 and ESIG2c primer set (Coplin et al. 2002).

e Conventional PCR using ESIG1 and ESIG2c primer set (Coplin et al. 2002).

${ }^{f}$ Real-time PCR using cps-RT74F and cps-177R primer set and cps-133 probe (Tambong et al. 2008).

g Conventional PCR using 356 and 341 primer set (Wensing et al. 2010).

h Conventional PCR using 383 and 385 primer set (Wensing et al. 2010).

i Real-time PCR using 340 and 354 primer set and 353 probe (Wensing et al. 2010).

j Real-time SYBR Green PCR with primers cpsAB2313F and cpsR (this study).

k PCR product not of expected size, or multiple bands were present. 
SYBR Green real-time PCR of bacterial strains. PCR amplifications of bacterial strains in Table 1 were performed by using $1 \mu l$ ( 25 to $30 \mathrm{ng} / \mu \mathrm{l}$ ) of purified genomic DNA, $5 \mu \mathrm{l}$ of the $2 \times$ concentrated master mix of B-R SYBR Green Supermix for iQ Systems (Quanta Biosciences), $0.4 \mu \mathrm{l}$ of $10 \mu \mathrm{mol} / \mathrm{liter}$ cpsAB2313F and cpsR primers, and $3.2 \mu \mathrm{l}$ of PCR-grade water in a total reaction volume of $10 \mu \mathrm{l}$. Amplification conditions were $95^{\circ} \mathrm{C}$ for $3 \mathrm{~min}$ and 40 cycles of $95^{\circ} \mathrm{C}$ for $15 \mathrm{~s}$ and $68^{\circ} \mathrm{C}$ for $45 \mathrm{~s}$ followed by a melt curve from $65^{\circ} \mathrm{C}$ to $95^{\circ} \mathrm{C}$ in increments of $0.5^{\circ} \mathrm{C}$ using a CFX 96 real-time PCR detection system with CFX Manager version 3.1 software (Bio-Rad Laboratories,

Table 1. (Continued from previous page)

\begin{tabular}{|c|c|c|c|c|c|c|c|c|c|c|c|c|c|c|}
\hline \multirow[b]{2}{*}{ Bacterial strain } & \multirow[b]{2}{*}{ Origin (source if known) } & \multirow{2}{*}{$\begin{array}{l}\text { Pathogenicity } \\
\text { in maize }\end{array}$} & \multirow{2}{*}{$\begin{array}{c}\text { SW } \\
\text { ELISA }\end{array}$} & \multicolumn{9}{|c|}{$\begin{array}{c}\text { Conventional and real-time PCR methods } \\
\text { (method } I \text { is the real-time PCR assay } \\
\text { developed in this study) }\end{array}$} & \multicolumn{2}{|c|}{$\begin{array}{l}\text { Biochemical } \\
\text { tests }\end{array}$} \\
\hline & & & & $\mathbf{A}^{\mathbf{b}}$ & $\mathbf{B}^{\mathrm{c}}$ & $\mathbf{C}^{\mathbf{d}}$ & $\mathbf{D}^{\mathbf{e}}$ & $\mathbf{E}^{\mathbf{f}}$ & $F^{g}$ & $\mathbf{G}^{\mathbf{h}}$ & $\mathbf{H}^{\mathbf{i}}$ & $\mathbf{I j}$ & Esculin & Indole \\
\hline $681-4$ & $\begin{array}{l}\text { Corn seed, Brazil, } 2010 \\
\text { (C. Block) }\end{array}$ & - & + & - & - & + & $+^{\mathrm{k}}$ & + & + & $+^{\mathrm{k}}$ & + & - & + & + \\
\hline $508-3$ & $\begin{array}{l}\text { Corn seed, HI, } 2011 \\
\text { (C. Block) }\end{array}$ & - & + & + & + & + & + & + & + & + & + & - & + & - \\
\hline $508-5$ & $\begin{array}{l}\text { Corn seed, HI, } 2011 \\
\text { (C. Block) }\end{array}$ & - & + & + & + & + & + & + & + & + & + & - & + & - \\
\hline $508-7$ & $\begin{array}{l}\text { Corn seed, HI, } 2011 \\
\text { (C. Block) }\end{array}$ & - & + & + & + & + & + & + & + & + & + & NT & + & - \\
\hline \multicolumn{15}{|l|}{ Pantoea agglomerans strains } \\
\hline PA99-3 & Georgia (R. Walcott) & - & - & - & - & - & - & - & - & $+^{\mathrm{k}}$ & - & - & + & - \\
\hline C9-1 & Georgia (R. Walcott) & - & - & - & - & - & - & - & - & - & - & - & + & - \\
\hline Pagg \#1 & ISU culture collection & - & - & - & - & - & - & - & - & - & + & - & + & - \\
\hline Pagg \#2 & ISU culture collection & - & - & - & - & - & - & - & - & - & - & - & + & - \\
\hline Pagg-F18 & Corn, IA (G. Beattie) & - & - & - & - & - & - & - & - & - & - & - & + & - \\
\hline Pagg-L9 & Corn, IA (G. Beattie) & - & - & - & - & - & - & - & - & - & - & - & + & - \\
\hline CPO-7 & $\begin{array}{l}\text { Sorg., Mexico } 2007 \\
\text { (H. Silva-Rojas) }\end{array}$ & - & - & - & - & - & - & - & - & - & - & - & + & - \\
\hline СРО-9 & $\begin{array}{l}\text { Corn, Mexico } 2007 \\
\text { (H. Silva-Rojas) }\end{array}$ & - & - & - & - & - & - & - & - & - & - & - & + & - \\
\hline СРО-16 & $\begin{array}{l}\text { Sorg., Mexico } 2007 \\
\text { (H. Silva-Rojas) }\end{array}$ & - & - & - & - & - & - & - & - & - & - & - & + & - \\
\hline CPO-36 & $\begin{array}{l}\text { Corn, Mexico } 2007 \\
\text { (H. Silva-Rojas) }\end{array}$ & - & - & - & - & - & - & - & - & - & - & - & + & - \\
\hline CPO-41 & $\begin{array}{l}\text { Corn, Mexico } 2007 \\
\text { (H. Silva-Rojas) }\end{array}$ & - & - & - & - & - & - & - & - & - & - & - & + & - \\
\hline \multicolumn{15}{|l|}{ Pantoea ananatis strains } \\
\hline DC130 & Corn, MO 1976 (S. Walker) & - & - & + & - & - & - & - & - & - & - & - & + & + \\
\hline ATCC-8366 & Insect gut (E. Steinhaus) & - & - & + & - & - & - & $+/-$ & - & + & + & - & + & + \\
\hline СPO-8 & $\begin{array}{l}\text { Corn, Mexico } 2007 \\
\text { (H. Silva-Rojas) }\end{array}$ & - & - & + & - & - & - & - & - & - & - & - & + & + \\
\hline CPO-12B & $\begin{array}{l}\text { Corn, Mexico } 2007 \\
\text { (H. Silva-Rojas) }\end{array}$ & - & - & + & - & - & - & - & - & - & - & - & + & + \\
\hline CPO-27B & $\begin{array}{l}\text { Corn, Mexico } 2007 \\
\text { (H. Silva-Rojas) }\end{array}$ & - & - & + & - & - & - & - & - & - & - & - & + & - \\
\hline $\mathrm{CPO}-47$ & $\begin{array}{l}\text { Corn, Mexico } 2007 \\
\text { (H. Silva-Rojas) }\end{array}$ & - & - & + & - & - & - & - & - & - & - & - & + & + \\
\hline CPO-95 & $\begin{array}{l}\text { Corn, Mexico } 2007 \\
\text { (H. Silva-Rojas) }\end{array}$ & - & - & + & - & - & - & - & - & - & - & - & + & + \\
\hline PNA97-1 & Melon, GA (R. Walcott) & - & - & + & - & - & - & - & $+/-$ & - & - & - & + & + \\
\hline PNA98-2 & Melon, GA (R. Walcott) & - & - & + & - & - & - & - & + & - & - & - & + & + \\
\hline ATCC-19321 & Wheat (D. Pon) & - & - & $+^{\mathrm{k}}$ & - & - & - & + & - & + & + & - & + & + \\
\hline ATCC-31225 & S. Lindow & - & - & $+^{\mathrm{k}}$ & + & + & - & + & + & + & + & - & + & + \\
\hline ATCC-35400 & Melon, CA (J. Wells) & - & - & $+^{\mathrm{k}}$ & + & + & + & - & $+^{\mathrm{k}}$ & $+^{\mathrm{k}}$ & + & - & + & $+/-$ \\
\hline NRRL B-133 & Wheat (E. Waldee) & - & + & $+^{\mathrm{k}}$ & - & $t^{\mathrm{k}}$ & + & + & + & + & + & - & + & $+/-$ \\
\hline \multicolumn{15}{|l|}{ Other isolates } \\
\hline EA-2, Erwinia amylovora & Apple, ISU culture collection & - & - & - & - & - & - & - & - & - & - & - & - & - \\
\hline $\begin{array}{l}\text { ECC } 1, \text { Pectobacterium } \\
\text { carotovorum }\end{array}$ & Carrot, ISU culture collection & - & - & - & - & - & - & - & - & - & - & - & + & - \\
\hline $\begin{array}{l}\text { ECA1, Pectobacterium } \\
\text { atroseptica }\end{array}$ & Potato, ISU culture collection & - & - & - & - & - & - & - & - & - & - & - & + & - \\
\hline ECP1, Erwinia cypripedii & Orchid, ISU culture collection & - & - & - & - & - & - & - & - & - & - & - & + & - \\
\hline AAA1, Acidovorax avenae & Corn, IA, 2008 (C. Block) & + & - & - & - & - & - & - & - & - & - & - & + & - \\
\hline $\begin{array}{l}\text { NE-S1, Xant. vasicola pv. } \\
\text { vasculorum }\end{array}$ & Corn, NE, 2016 (C. Block) & + & - & + & - & - & - & - & - & - & - & - & + & - \\
\hline $\begin{array}{l}\text { 005B, Pseud. syr. pv. } \\
\text { syringae }\end{array}$ & Corn, NE, 2016 (C. Block) & + & - & $+^{\mathrm{k}}$ & - & - & - & - & - & $+^{\mathrm{k}}$ & - & - & + & - \\
\hline
\end{tabular}


Inc.). A nontemplate control (NTC) of PCR-grade water was included in all runs.

Standard curves. Standard curves were generated with 10-fold serial dilutions of genomic DNA (1 pg to $10 \mathrm{ng}$ ) and 10-fold serially diluted cell suspensions $\left(10^{4}\right.$ to $\left.10^{8} \mathrm{CFU} / \mathrm{ml}\right)$ of $P$. stewartii subsp. stewartii strain DC283. The experiment was repeated three times.

Specificity and sensitivity of real-time PCR. The specificity of the assay was determined by using 25 to $30 \mathrm{ng}$ of purified genomic DNA from 26 isolates of $P$. stewartii subsp. stewartii, 17 isolates of $P$. stewartii subsp. indologenes, 11 isolates of $P$. agglomerans, 13 isolates of $P$. ananatis, and 7 non-Pantoea isolates (Table 1 ). Sensitivity was determined with serial 10 -fold dilutions of purified genomic DNA of $P$. stewartii subsp. stewartii strain DC283 ranging from $1 \mathrm{fg}$ to $10 \mathrm{ng}$. A second 10 -fold dilution series $\left(10^{2}\right.$ to $\left.10^{8} \mathrm{CFU} / \mathrm{ml}\right)$ of cell suspension of freshly cultured $P$. stewartii subsp. stewartii strain DC283 was prepared in autoclaved milliQ water and adjusted to an initial optical density measured at $600 \mathrm{~nm}\left(\mathrm{OD}_{600}\right)$ of 0.2 . Repeatability of the assay was evaluated by testing the samples in duplicate (or triplicate) and in two independent runs.

Statistical analysis. PCR amplification efficiency was calculated from slopes of standard curves using the formula $E=100 \times$ $\left[\left(10^{-1 / \text { slope }}\right)-1\right]$. An $F$ test from one-way analysis of variance was used to test for significance of difference among the slopes of standard curves generated from real-time PCR on serial dilutions of $P$. stewartii subsp. stewartii strain DC283 cell suspension prepared in the matrix of water or nonconcentrated seed wash. Differences were considered significant at $P \leq 0.05$. The coefficient of variation $(\mathrm{CV})$ was calculated by using the following formula: standard deviation/mean $\times 100$, where the standard deviation is the root mean square deviation of the cycle threshold $(\mathrm{Ct})$ values from their arithmetic mean.

Evaluation of potential inhibitors in seed wash extracts on real-time PCR. A 10-fold dilution series was prepared by diluting freshly cultured $P$. stewartii subsp. stewartii strain DC283 cell suspension (adjusted to an initial $\mathrm{OD}_{600}$ of 0.2 ) in autoclaved milliQ water. Another 10-fold dilution series was prepared by diluting the same cell suspension in nonconcentrated seed wash from Stewart's wilt-negative corn accession Ames 23469 02ncai01. The Stewart's wilt-negative status of corn accession Ames 23469 02ncai01 was confirmed by a negative field observation (no disease symptoms on the seed parent plants) and a negative ELISA seed assay. PCR amplification was performed by using $1 \mu \mathrm{l}$ of each dilution in a total reaction volume of $10 \mu \mathrm{l}$; it was run under the following conditions: $95^{\circ} \mathrm{C}$ for $10 \mathrm{~min}, 45$ cycles of $95^{\circ} \mathrm{C}$ for $10 \mathrm{~s}$ and $68^{\circ} \mathrm{C}$ for $45 \mathrm{~s}$, and melting curve of $65^{\circ} \mathrm{C}$ to $95^{\circ} \mathrm{C}$ with increments of $0.5^{\circ} \mathrm{C}$ using a CFX96 realtime PCR system (Bio-Rad Laboratories, Inc.). Each of the five

Table 2. Real-time polymerase chain reaction (PCR) assay of seed harvested from Pantoea stewartii subsp. stewartii-infected plants using cpsAB2313F and $\operatorname{cpsR}_{\text {primers }}{ }^{\mathrm{a}}$

\begin{tabular}{|c|c|c|c|}
\hline \multirow[b]{2}{*}{ Corn accessions } & \multirow[b]{2}{*}{ Stewart's wilt ELISA on seeds ${ }^{b}$} & \multicolumn{2}{|c|}{ Real-time PCR, ${ }^{\mathrm{c}}$ mean $\mathrm{Ct} \pm \mathrm{SD}$} \\
\hline & & Concentrated seed wash & Nonconcentrated seed wash \\
\hline PI 550532 99ncai01 & POS & $19.70 \pm 0.09$ & $26.58 \pm 0.57$ \\
\hline Ames 27025 05ncai01 & POS & $21.66 \pm 0.21$ & $26.47 \pm 0.18$ \\
\hline PI 658075 09ncao01 & POS & $23.76 \pm 0.47$ & $26.90 \pm 0.02$ \\
\hline PI 550481 99ncai01 & POS & $27.00 \pm 0.69$ & $32.90 \pm 0.47$ \\
\hline PI 607512 99ncab01 & POS & $27.39 \pm 0.42$ & $35.40 \pm 0.0$ \\
\hline PI 658081 09ncao01 & POS & $27.41 \pm 0.49$ & $34.72 \pm 1.27$ \\
\hline Ames 25222 99ncai01 & POS & $27.44 \pm 0.0$ & $30.53 \pm 0.06$ \\
\hline PI 595367 00ncai01 & POS & $27.65 \pm 0.20$ & $32.26 \pm 0.49$ \\
\hline Ames 14112 99ncai01 & POS & $28.17 \pm 0.32$ & $35.50 \pm 1.32$ \\
\hline PI 479129 99ncai01 & POS & $28.60 \pm 0.39$ & $34.13 \pm 0.04$ \\
\hline PI 608768 98ncai01 & POS & $28.70 \pm 0.30$ & $33.39 \pm 0.19$ \\
\hline PI 180166 92ncab01 & POS & $29.24 \pm 0.36$ & $32.95 \pm 0.06$ \\
\hline PI 658078 09ncao01 & POS & $29.42 \pm 0.0$ & $34.29 \pm 0.33$ \\
\hline PI 587140 92ncai01 & POS & $29.80 \pm 0.22$ & $36.08 \pm 0.82$ \\
\hline NSL 65865 99ncai01 & POS & $30.26 \pm 0.10$ & $34.38 \pm 0.45$ \\
\hline Ames 27087 04ncai01 & POS & $30.26 \pm 0.74$ & $35.35 \pm 0.28$ \\
\hline PI 586701 06ncai01 & POS & $30.26 \pm 0.93$ & $33.94 \pm 0.84$ \\
\hline Ames 19313 92ncai01 & POS & $30.76 \pm 0.30$ & $38.20 \pm 0.20$ \\
\hline PI 542778 99ncai01 & POS & $30.76 \pm 0.36$ & $38.30 \pm 0.11$ \\
\hline PI 594077 00ncai01 & POS & $32.96 \pm 0.35$ & $37.78 \pm 0.35$ \\
\hline PI 311249 00ncai01 & POS & $32.96 \pm 1.12$ & $35.24 \pm 0.48$ \\
\hline PI 614142 99ncai01 & POS & $33.60 \pm 0.11$ & $38.99 \pm 0.25$ \\
\hline PI 479197 99ncai01 & POS & $34.14 \pm 0.55$ & $36.16 \pm 1.32$ \\
\hline PI 531495 06ncai01 & POS & $35.34 \pm 0.19$ & $39.54 \pm 0.63$ \\
\hline PI 639502 03ncai01 & POS & $36.44 \pm 1.87$ & N/A \\
\hline Ames 22039 04ncai01 & POS & $36.97 \pm 0.22$ & N/A \\
\hline PI 479150 99ncai01 & POS & $38.17 \pm 1.18$ & 43.83 \\
\hline PI 594051 00ncai01 & POS & $41.42 \pm 0.79$ & N/A \\
\hline PI 600755 98ncai01 & POS & $43.45 \pm 0.0$ & N/A \\
\hline PI 232963 04ncai01 & POS & N/A & N/A \\
\hline PI 597927 04ncai02 & POS & N/A & N/A \\
\hline \multicolumn{4}{|l|}{ Negative control lots } \\
\hline Ames 27185 15ncai01 & NEG & N/A & N/A \\
\hline Ames 28954 08ncai01 & NEG & N/A & N/A \\
\hline PI 221846 00ncai01 & NEG & N/A & N/A \\
\hline PI 548802 12ncai01 & NEG & N/A & N/A \\
\hline PI 558533 92ncai01 & NEG & N/A & N/A \\
\hline
\end{tabular}

${ }^{a}$ N/A, not applicable (no observed Ct value); NEG, no detection; POS, positive detection of $P$. stewartia; SD, standard deviation.

${ }^{\mathrm{b}}$ Enzyme-linked immunosorbent assay (ELISA) tests were performed according to the manufacturer's recommendations (Agdia Inc.).

c Samples were considered positive for $P$. stewartii subsp. stewartii when mean cycle threshold (Ct) value was $<40$ of 45 amplification cycles (values are means of two replicates) 
dilutions (ranging from $10^{4}$ to $10^{8} \mathrm{CFU} / \mathrm{ml}$ ) spiked in the background solution of water or nonconcentrated seed wash was run in triplicate, and the experiment was conducted twice. Standard curves were generated by plotting $\mathrm{Ct}$ values versus $\log _{10} \mathrm{CFU}$ per milliliter cell suspension spiked in water or seed wash, and slopes of the linear regression lines were compared by statistical analysis.

SYBR Green real-time PCR on seed wash extracts from corn seed. Fifty-seven corn seed lots were tested by the P. stewartii

Table 3. Real-time polymerase chain reaction (PCR) with cpsAB2313F and cpsR primer pair on corn seed lots of tropical or subtropical origin that tested positive with the Stewart's wilt enzyme-linked immunosorbent assay (ELISA) ${ }^{\mathrm{a}}$

\begin{tabular}{|c|c|c|c|c|c|}
\hline Corn seed lots & $\begin{array}{l}\text { Seed production } \\
\text { location }\end{array}$ & $\begin{array}{l}\text { Stewart's wilt symptoms on } \\
\text { parent plants in the field }\end{array}$ & $\begin{array}{c}\text { Stewart's wilt ELISA on } \\
\text { seeds }{ }^{\text {b }}\end{array}$ & $\begin{array}{l}\text { Real-time PCR on seed } \\
\text { wash }^{c}\end{array}$ & $\begin{array}{c}\text { Conventional PCR } \\
\text { product size, bp }\end{array}$ \\
\hline $\begin{array}{l}\text { A-28655 } \\
\text { (Commercial) }\end{array}$ & Puerto Rico & NEG & POS & $\operatorname{NEG}(\mathrm{Ct}=\mathrm{N} / \mathrm{A})$ & 193 \\
\hline $\begin{array}{l}\text { A-28653 } \\
\text { (Commercial) }\end{array}$ & Puerto Rico & NEG & POS & $\operatorname{NEG}(\mathrm{Ct}=\mathrm{N} / \mathrm{A})$ & 193 \\
\hline $\begin{array}{l}\text { A-28651 } \\
\text { (Commercial) }\end{array}$ & Puerto Rico & NEG & POS & $\mathrm{NEG}(\mathrm{Ct}=\mathrm{N} / \mathrm{A})$ & 193 \\
\hline $\begin{array}{l}\text { A- } 28650 \\
\text { (Commercial) }\end{array}$ & Puerto Rico & NEG & POS & $\mathrm{NEG}(\mathrm{Ct}=\mathrm{N} / \mathrm{A})$ & 193 \\
\hline $\begin{array}{l}\text { A-28649 } \\
\text { (Commercial) }\end{array}$ & Puerto Rico & NEG & POS & $\operatorname{NEG}(\mathrm{Ct}=\mathrm{N} / \mathrm{A})$ & 193 \\
\hline $\begin{array}{l}\text { A- } 28645 \\
\text { (Commercial) }\end{array}$ & Puerto Rico & NEG & POS & $\mathrm{NEG}(\mathrm{Ct}=\mathrm{N} / \mathrm{A})$ & 193 \\
\hline $\begin{array}{l}\text { Ames } 32321 \\
16 \text { ncei01 }\end{array}$ & Puerto Rico & NEG & POS & $\mathrm{NEG}(\mathrm{Ct}=\mathrm{N} / \mathrm{A})$ & 193 \\
\hline $\begin{array}{l}\text { Ames } 32327 \\
15 \text { ncei01 }\end{array}$ & St. Croix, U.S.A. & NEG & POS & $\operatorname{NEG}(\mathrm{Ct}=\mathrm{N} / \mathrm{A})$ & 193 \\
\hline $\begin{array}{r}\text { PI } 478954 \\
15 \text { ncei01 }\end{array}$ & Puerto Rico & NEG & POS & $\operatorname{NEG}(\mathrm{Ct}=\mathrm{N} / \mathrm{A})$ & 193 \\
\hline $\begin{array}{r}\text { PI } 494936 \\
15 \text { ncei01 }\end{array}$ & Puerto Rico & NEG & POS & $\operatorname{NEG}(\mathrm{Ct}=\mathrm{N} / \mathrm{A})$ & 193 \\
\hline $\begin{array}{r}\text { PI } 503900 \\
15 \text { ncei01 }\end{array}$ & Puerto Rico & NEG & POS & $\mathrm{NEG}(\mathrm{Ct}=\mathrm{N} / \mathrm{A})$ & 193 \\
\hline $\begin{array}{r}\text { PI } 511656 \\
15 \text { ncei01 }\end{array}$ & Puerto Rico & NEG & POS & $\mathrm{NEG}(\mathrm{Ct}=\mathrm{N} / \mathrm{A})$ & 193 \\
\hline $\begin{array}{r}\text { PI } 593012 \\
10 \text { ncei01 }\end{array}$ & Puerto Rico & NEG & POS & $\operatorname{NEG}(\mathrm{Ct}=\mathrm{N} / \mathrm{A})$ & 193 \\
\hline $\begin{array}{r}\text { PI } 641239 \\
12 \text { ncei } 01\end{array}$ & St. Croix, U.S.A. & NEG & POS & $\mathrm{NEG}(\mathrm{Ct}=\mathrm{N} / \mathrm{A})$ & 193 \\
\hline $\begin{array}{r}\text { PI } 641245 \\
10 \text { ncei01 }\end{array}$ & Puerto Rico & NEG & POS & $\mathrm{NEG}(\mathrm{Ct}=\mathrm{N} / \mathrm{A})$ & 193 \\
\hline $\begin{array}{r}\text { PI } 331452 \\
14 \text { ncei01 }\end{array}$ & Hawaii & NEG & POS & $\mathrm{NEG}(\mathrm{Ct}=\mathrm{N} / \mathrm{A})$ & 193 \\
\hline $\begin{array}{r}\text { PI } 498644 \\
15 \text { ncei01 }\end{array}$ & Puerto Rico & NEG & POS & $\operatorname{NEG}(\mathrm{Ct}=\mathrm{N} / \mathrm{A})$ & 193 \\
\hline $\begin{array}{r}\text { PI } 628461 \\
15 \text { ncei01 }\end{array}$ & Puerto Rico & NEG & POS & $\operatorname{NEG}(\mathrm{Ct}=\mathrm{N} / \mathrm{A})$ & 193 \\
\hline
\end{tabular}

Table 4. Comparison of extraction procedures for real-time polymerase chain reaction (PCR) detection of Pantoea stewartii subsp. stewartii in corn seeds ${ }^{\mathrm{a}}$

\begin{tabular}{|c|c|c|c|c|c|c|c|}
\hline \multirow[b]{4}{*}{$\begin{array}{l}\text { SW-positive seed } \\
\text { lots }^{\mathbf{b}}\end{array}$} & \multicolumn{7}{|c|}{ Real-time PCR, mean $\mathrm{Ct} \pm \mathrm{SD}$} \\
\hline & \multicolumn{6}{|c|}{ Whole seeds ${ }^{c}$} & \multirow{3}{*}{$\begin{array}{c}\text { Seeds ground in } \\
\text { water or } 1 \times \text { PBS } \\
\text { (nonconcentrated } \\
\text { seed wash) }\end{array}$} \\
\hline & \multicolumn{2}{|c|}{$1 \times$ PBS } & \multicolumn{2}{|c|}{$\begin{array}{c}\text { Saline }(0.85 \% \text { NaCl}) \text { with } \\
0.02 \% \text { Tween-20 }\end{array}$} & \multicolumn{2}{|c|}{ Deionized (milliQ) water } & \\
\hline & $\begin{array}{l}\text { Nonconcentrated } \\
\text { seed wash }^{\mathbf{d}}\end{array}$ & $\begin{array}{l}\text { Concentrated } \\
\text { seed wash }\end{array}$ & $\begin{array}{l}\text { Nonconcentrated } \\
\text { seed wash }\end{array}$ & $\begin{array}{l}\text { Concentrated } \\
\text { seed wash }\end{array}$ & $\begin{array}{l}\text { Nonconcentrated } \\
\text { seed wash }\end{array}$ & $\begin{array}{l}\text { Concentrated } \\
\text { seed wash }\end{array}$ & \\
\hline $\begin{array}{l}\text { Seed lot LN1(3.5\% } \\
\text { kernel infection) }\end{array}$ & N/A & $37.30 \pm 1.97$ & N/A & $28.00 \pm 0.37$ & N/A & $32.41 \pm 1.44$ & N/A \\
\hline $\begin{array}{c}\text { Seed lot AN1 (9\% } \\
\text { kernel infection) }\end{array}$ & N/A & $36.28 \pm 1.30$ & N/A & $36.48 \pm 0.78$ & $33.7 \pm 0.39$ & $27.10 \pm 0.24$ & N/A \\
\hline $\begin{array}{l}\text { Seed lot AR4 (37\% } \\
\text { kernel infection) }\end{array}$ & N/A & $27.10 \pm 0.64$ & N/A & $21.71 \pm 0.01$ & $29.55 \pm 0.37$ & $23.77 \pm 0.37$ & N/A \\
\hline
\end{tabular}


ELISA (Agdia Inc.) and SYBR Green real-time PCR. This included 31 seed lots (Table 2) harvested from known P. stewartii subsp. stewartii-infected field plants (infection verified during phytosanitary field inspection), 5 negative control seed lots from noninfected field plots (Table 2), and 18 seed lots from Puerto Rico, St. Croix, and Hawaii that showed no Stewart's wilt symptoms in field inspections but seed tested positive by ELISA (Table 3).

Fifty untreated whole corn seeds per seed lot were incubated with $50 \mathrm{ml}$ of autoclaved milliQ water in sterile flasks at room temperature on a shaker at $160 \mathrm{rpm}$ for $4 \mathrm{~h}$. A $1,200-\mu \mathrm{l}$ aliquot was removed and centrifuged at 1,000 RCF for 3 min to pellet corn debris; then, $1,100 \mu \mathrm{l}$ of the supernatant was transferred to a new tube. Direct PCR amplification of the nonconcentrated water extracts was performed by using $2 \mu \mathrm{l}$ of supernatant, $5 \mu \mathrm{l}$ of the $2 \times$ concentrated master mix of B-R SYBR Green Supermix for iQ Systems (Quanta Biosciences), $0.4 \mu \mathrm{l}$ of $10 \mu \mathrm{mol} /$ liter of each of the cpsAB2313F and cpsR primers, and $2.2 \mu \mathrm{l}$ of PCR-grade water in a total reaction volume of $10 \mu \mathrm{l}$ under the conditions $95^{\circ} \mathrm{C}$ for $10 \mathrm{~min}, 45$ cycles of $95^{\circ} \mathrm{C}$ for $10 \mathrm{~s}$ and $68^{\circ} \mathrm{C}$ for $45 \mathrm{~s}$, and melting curve of $65^{\circ} \mathrm{C}$ to $95^{\circ} \mathrm{C}$ with increments of $0.5^{\circ} \mathrm{C}$ using a CFX96 real-time PCR detection

DC283 GCCATTTTGTTCAAAACCGTCGGTGTCGTGCTTAAGCGTGATGGTGCTTATTAACCGCAG LMG2632 GCCATTTTGTTCAAAACCGTCGGTGTCGTGCTTAAGCGTGATGGTGCTTATTAACCGCAG cpsF

DC283 GAAAAAGGTGCCAGCCTCTCTCTGACAGCACACGACAGGGGAGCGGGTTGGTACATTTTT LMG2632 GAAAAAGGTGCCAGCCTCTCTCTGACAGCACACGACAGGGGAGCGGGTTGGTACATTTTT

DC283 CTAAAAAAAAGCGGCTTTGTTGAATAATAGGTAATCATTCTGTTTTGTCTGCACTGTTTT

LMG2632 CTAAAAAA--

cpsAB2313F

DC283 GGTAGAAAACGCTGATGCCAGACAGAACACCGTCATACGCAAGCATGTAATGCATTGATT LMG2632

DC283 TTATGTTATCTGAAACAACCGTTTTCATAGTACCACAGCATAAAATCCATTTATTCAACA LMG2632

DC283 AAGCCAAAAAAAGCGGTACGGCATTGATAAACAGCAATGTTCTGCTTTGCTTTATTTATT LMG2632 -----------AAGCGGTACGGCATTGATAAACAGCCATGTTCTGCTTTGCTTTATTTCTT

DC283 TCTGGGTAAAGCGCGTGATCGGTAAAAGACAGGAGCTAAGAATAATGAACGACATGTTCA LMG2632 TCTGGGTAAAGCGCGTGATCGGTAAAAGACAGGAGCTAAGAATAATGAACGACATGTTCA CpsR

DC283 GTGCCTGAGTCAGGATAGTTTACTTTTTTTGAGCGCTTACACAGCGGCGTACTTGCCTCT LMG2632 GTGCCTGAGTCAGGATAGTTTACTTTTTTTGAGCGCTTACACAGCGGCGTACTTGCCTCT

DC283 ATCAAACATTAACTGATAGCGAAGATCTAAATGATTACAATGAAAATGAAGATGATACCT LMG2632 ATCAAACATTAACTGATAGCGAAGATCTAAATGATTACAATGAAAATGAAGATGATACCT start codon

Fig. 1. Alignment of intergenic nucleotide sequence between the $c p s A$ and $c p s B$ genes of Pantoea stewartii subsp. stewartii strain DC283 (GenBank accession number CP017581) with Pantoea stewartii subsp. indologenes strain LMG2632 (GenBank accession number JPK001000031) using Clustal Omega. Dashes indicate the 182-bp sequence deletion in strain LMG2632. The stop codon of $c p s A$ gene and the start codon of $c p s B$ gene are highlighted. Primer binding site sequences are in bold and underlined with primer names above the sequence. 
system with CFX Manager version 3.1 software (Bio-Rad Laboratories, Inc.). An NTC using PCR-grade water was included in all runs to monitor contamination.

For the concentrated seed extracts, after the same 3-min centrifugation at 1,000 RCF to pellet corn debris, the supernatant was transferred to a new tube and further centrifuged at 13,000 RCF for $10 \mathrm{~min}$ to pellet any bacteria. The supernatant was completely removed with a pipette, and $20 \mu \mathrm{l}$ of TE (10 mM Tris, $1 \mathrm{mM}$ EDTA, $\mathrm{pH}$ 8.0) buffer was added to the pellet. The tube was vortexed for $10 \mathrm{~s}$ and heated in a water bath at $95^{\circ} \mathrm{C}$ for $10 \mathrm{~min}$ to disrupt the bacterial cells. After cooling for $5 \mathrm{~min}$, the tubes were centrifuged at 13,000 $\mathrm{RCF}$ for $3 \mathrm{~min}$ to pellet any cell debris, and the supernatant containing DNA was transferred to a new tube; $2 \mu l$ of this DNA suspension was used for real-time PCR. Amplifications were performed with the same protocol described for the nonconcentrated seed wash, except for initial denaturation at $95^{\circ} \mathrm{C}$ for $3 \mathrm{~min}$.

Because several bacterial species, including those in genera Pantoea, Pseudomonas, Burkholderia, Paenibacillus, Enterobacter, Acetinobacter, and Sphingomonas, have been reported to be present on or inside corn seeds (Johnston-Monje and Raizada 2011; Liu et al. 2012) as part of resident bacterial community, a separate real-time PCR reaction targeting the $16 \mathrm{~S}$ ribosomal RNA gene sequence was performed with the universal bacterial primers $968 \mathrm{~F}$ (5'-GAACGC GAAGAACCTTAC-3') (Lane 1991) and 1492R (5'-TGACTGACT GAGGYTACCTTGTTACGACTT-3') (Nübel et al. 1996) to check for PCR inhibition in the concentrated seed wash extracts. Extracts from 25 of the 57 seed lots were tested with the universal bacterial primers, including 16 lots of tropical/subtropical origin, 5 P. stewartii subsp. stewartii-negative control seed lots, and 4 P. stewartii subsp. stewartii-positive control seed lots. PCR amplifications were performed with $2 \mu \mathrm{l}$ of DNA suspension from the concentrated seed wash, $5 \mu \mathrm{l}$ of the $2 \times$ master mix of B-R SYBR Green Supermix for iQ Systems (Quanta Biosciences), $0.4 \mu \mathrm{l}$ of $10 \mu \mathrm{mol}$ liter $^{-1}$ 968F and 1492R primers, and $2.2 \mu \mathrm{l}$ of PCR-grade water in a total reaction volume of $10 \mu \mathrm{l}$ under the following conditions: $95^{\circ} \mathrm{C}$ for $3 \mathrm{~min} ; 40$ cycles of $95^{\circ} \mathrm{C}$ for $15 \mathrm{~s}, 55^{\circ} \mathrm{C}$ for $30 \mathrm{~s}$, and $72^{\circ} \mathrm{C}$ for $1 \mathrm{~min}$; and melting curve of $65^{\circ} \mathrm{C}$ to $95^{\circ} \mathrm{C}$ with increments of $0.5^{\circ} \mathrm{C}$ using a CFX96 real-time PCR system (Bio-Rad Laboratories, Inc.).

Conventional PCR. If a seed lot tested positive by the Stewart's wilt ELISA and negative by the P. stewartii subsp. stewartii-specific real-time PCR, a conventional PCR was performed with primer pair cpsF/cpsR (Thapa et al. 2012). The presence of a single 193-bp amplicon indicated the presence of $P$. stewartii subsp. indologenes and confirmed the absence of $P$. stewartii subsp. stewartii (375-bp amplicon expected). Conventional PCR was carried out with $2 \mu \mathrm{l}$ of DNA suspension from the concentrated seed wash or $5 \mu$ l of nonconcentrated water extract, $7.5 \mu \mathrm{l}$ of $2 \times$ concentrated GoTaq Green master mix (Promega), and $0.5 \mu \mathrm{l}$ of $10 \mu \mathrm{mol} / \mathrm{liter}$ each primer in a total reaction volume of $15 \mu \mathrm{l}$ under the following conditions: $95^{\circ} \mathrm{C}$ for $3 \mathrm{~min}$ and 40 cycles of $95^{\circ} \mathrm{C}$ for $20 \mathrm{~s}, 60^{\circ} \mathrm{C}$ for $30 \mathrm{~s}$, and $72^{\circ} \mathrm{C}$ for 1 min using the MyCycler thermal cycler (Bio-Rad Laboratories, Inc.). PCR products were run on a $2 \%$ agarose gel containing GelRed stain (Biotium Inc.).

Sanger sequencing of PCR products. PCR products generated from real-time and conventional PCR were purified with a PCR clean-up/gel extraction kit (IBI Scientific) and sequenced using the cpsR reverse primer at the Iowa State University DNA Sequencing Facility.

\section{Results}

Evaluation of ELISA and PCR methods for detection of $\boldsymbol{P}$. stewartii subsp. stewartii. All 26 P. stewartii subsp. stewartii isolates were pathogenic on Stewart's wilt-susceptible corn inbred Mt42 seedlings, except for two known avirulent isolates GalE8 and Mu51 (Coplin et al. 2002). Little variation was seen among isolates, because they all tested positive by ELISA, were amplified by all nine PCR primer sets, and were negative for esculin and indole reactions (Table 1). The 11 P. agglomerans isolates were nonpathogenic on Mt42 corn, ELISA negative, and PCR negative on assays A to I except for isolate PA99-3, which was positive on assay G, and Pagg\#1, which was positive on assay H. All 11 P. agglomerans isolates were positive for esculin hydrolysis and negative for indole reaction (Table 1). The $P$. ananatis isolates were nonpathogenic on corn, ELISA negative (except for a weak positive reaction with NRRL B-133), esculin positive, and mostly positive for indole reaction (three indeterminate reactions). PCR assay A (Coplin et al. 2002), which targets the $c p s D$ gene, produced amplicons from all $10 P$. ananatis isolates. Most of the $P$. ananatis isolates were PCR negative on assays B to I; however, isolate NRL B-133 and three ATCC isolates (19321, 31225, and 35400) produced amplicons with multiple primer sets (Table 1), although not always of the expected amplicon size.

A total of 17 (10 from corn seed and 7 from other hosts) P. stewartii subsp. indologenes isolates were tested. The 10 corn strains (645-3, 645-10, 645-14, 649-2, 651-3, 655-2B-Y1, 681-4, 508-3, 508-5, and 508-7) represented corn seed lots from Brazil, Hawaii, and Puerto Rico. All 17 P. stewartii subsp. indologenes isolates were nonpathogenic on Mt42 corn and esculin positive; 14 of 17 were indole positive, with exceptions for isolate 0696-16 from sorghum and isolates 508-3, 508-5, and 508-7 from Hawaii-grown corn. Thirteen of 17 were motile (data not shown), whereas all 26 P. stewartii subsp. stewartii were nonmotile. Interestingly, all 7 isolates from nonmaize hosts were ELISA negative, but 9 of the 10 isolates from corn seed tested positive by ELISA. All P. stewartii subsp. indologenes isolates yielded PCR products from at least six of the nine PCR assays (Table 1), although the amplicons were not always of the expected size or multiple PCR products were observed. The only consistently negative assay for the $P$. stewartii subsp. indologenes isolates was assay I, which was developed in this study.

In summary, although ELISA and the nine tested PCR primer sets were found to be effective for identifying P. stewartii subsp. stewartii, sets A to $\mathrm{H}$ frequently yielded false positive results with $P$. stewartii subsp. indologenes isolates and gave scattered positive reactions from $P$. ananatis and occasional $P$. agglomerans isolates (Table 1). The indole test performed reasonably well in helping to separate $P$. stewartii subsp. stewartii strains (indole negative) from $P$. stewartii subsp. indologenes (most were indole positive). The esculin hydrolysis test was even better; it was $100 \%$ effective in distinguishing $P$. stewartii subsp. stewartii (esculin negative) from $P$. stewartii subsp. indologenes (esculin positive) strains.

Comparison of extraction procedures. Three matrices (PBS buffer, saline plus Tween, and deionized water) were compared for their efficiency in extracting $P$. stewartii subsp. stewartii from corn seeds. When $\mathrm{Ct}$ values for nonconcentrated seed washes (direct PCR from seed wash extracts) were compared, no amplification occurred from the PBS and saline seed wash extracts (mean $\mathrm{Ct}=$ not applicable [N/A]) (Table 4), but two of the three water extracts (AN1 and AR4) were positive. In the concentrated seed wash extracts (high-speed centrifugation and resuspension of pellet), all three seed lots were positive (Table 4), although the sensitivity of detection varied among the extraction matrices. The $\mathrm{Ct}$ values for water extracts were three to nine cycles lower (more sensitive) than the corresponding PBS extracts. Two of the three saline extracts (LN1 and AR4) actually had lower mean $\mathrm{Ct}$ values than their corresponding water extracts, but water extracts were generally superior for direct detection from nonconcentrated seed washes.

With ground seeds, whether incubated in sterile PBS or water and used directly in real-time PCR, no amplification (mean $\mathrm{Ct}=\mathrm{N} / \mathrm{A}$ ) was observed for any of the three seed lots (Table 4). Seed components, such as polysaccharides, polyphenols, alkaloids, or tannins, present in the ground seed extracts may have inhibited PCR amplification.

Standard curves. A standard curve of mean $\mathrm{Ct}$ value versus the $\log _{10}$ concentration of DC283 genomic DNA (1 pg to $10 \mathrm{ng}$ ) showed a linear correlation $\left(R^{2}=0.998\right.$, slope $\left.=-3.58\right)$ and a PCR efficiency of $90.25 \%$ (Fig. 2A). The standard curve of $\mathrm{Ct}$ value versus bacterial cell concentration $\left(10^{4}\right.$ to $\left.10^{8} \mathrm{CFU} / \mathrm{ml}\right)$ showed a linear correlation $\left(R^{2}=0.993\right.$, slope $\left.=-3.483\right)$ with a PCR efficiency of $93.69 \%$ (Fig. 2B). 
Specificity, sensitivity, and repeatability of SYBR Green real-time PCR. Diagnostic specificity of the assay was $100 \%$ for the 26 P. stewartii subsp. stewartii strains tested (Table 1). All strains showed positive amplification with a melting temperature of $80.5^{\circ} \mathrm{C}$
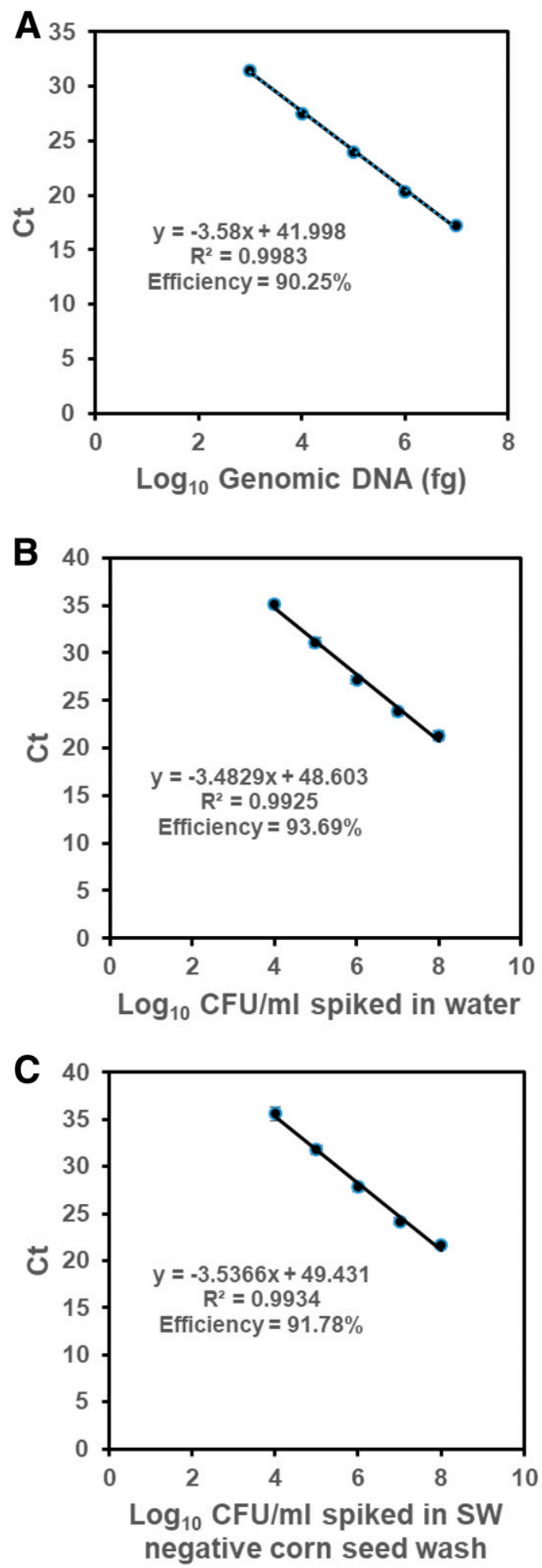

Fig. 2. Standard curves of real-time polymerase chain reaction assay with cycle threshold (Ct) values plotted against A, 10-fold serial dilutions of Pantoea stewartii subsp. stewartii strain DC283 purified genomic DNA starting with $10 \mathrm{ng}$, B, bacterial cells spiked in nuclease free water starting with $10^{8} \mathrm{CFU} / \mathrm{ml}$, and C, bacterial cells spiked in seed wash from Stewart's wilt (SW)-negative corn seeds starting with $10^{8} \mathrm{CFU} / \mathrm{ml}$. Values represent mean $\mathrm{Ct}$ from a total of three replicates (three independent runs) for genomic DNA and six replicates (two runs with three replicates each) for bacterial cells spiked in water or seed wash. Error bars represent standard deviation. Linear regression equations $(y=$ $a+b x)$ are displayed on the graphs. $R^{2}$ indicates coefficient of correlation.
(Fig. $3 \mathrm{~A}$ and B). Agarose gel electrophoresis confirmed the presence of an amplicon of the expected 256-bp size. The mean $\mathrm{Ct}$ values ranged from $13.11 \pm 0.6$ to $18.95 \pm 0.5$ for the $P$. stewartii subsp. stewartii strains (data not shown). No amplification $(\mathrm{Ct}=\mathrm{N} / \mathrm{A})$ was observed for all other Pantoea spp., including 16 isolates of $P$. stewartii subsp. indologenes, 11 isolates of $P$. agglomerans, and 13 isolates of $P$. ananatis. All seven non-Pantoea isolates also tested negative (mean $\mathrm{Ct}=$ N/A).

The minimum detection level calculated from the standard curves was $\sim 0.1 \mathrm{pg}$ for genomic DNA (17 genome equivalents per reaction; genome size $=5,233,214 \mathrm{bp}$ ) with a mean $\mathrm{Ct}$ value of 35.11 and 2.6 CFU per reaction for bacterial cell suspension (Fig. $2 \mathrm{~A}$ and B).

Repeatability of the real-time PCR assay was evaluated by testing five serial 10-fold dilutions of strain DC283 cell suspension $\left(10^{4}\right.$ to $10^{8} \mathrm{CFU} / \mathrm{ml}$ ) spiked in water in two independent real-time PCR runs with three replicates per run. The within-run $\mathrm{CV}$ was $<2.4 \%$, whereas the between-run $\mathrm{CV}$ was $<2.8 \%$.

Evaluation of potential inhibitors in seed wash extracts on real-time PCR. Standard curves showed a linear correlation between $\mathrm{Ct}$ values and $\log _{10}$ bacterial cells mixed into water $\left(R^{2}=0.993\right.$, slope $=$ -3.483 , PCR efficiency $=93.69 \%$ ) (Fig. 2B) or mixed with negative corn seed wash water extract $\left(R^{2}=0.993\right.$, slope $=-3.536$, PCR efficiency $=$ $91.78 \%)$ (Fig. 2C). No significant difference $(P$ value $=0.84)$ was found between the slopes of two standard curves, indicating little or no inhibition owing to seed constituents in the seed wash.

Corn seed lots that tested negative with the $P$. stewartii subsp. stewartii-specific real-time PCR assay (Tables 2 and 3) still tested positive for the $16 \mathrm{~S}$ ribosomal DNA amplicon ( $~ 524 \mathrm{bp})$ with universal bacterial primer set $968 \mathrm{~F}$ and $1492 \mathrm{R}$ (Supplementary Table S1), having a melt temperature of $86.5 \pm 0.5^{\circ} \mathrm{C}$. The results confirmed that bacteria other than $P$. stewartii subsp. stewartii were present in the samples and amplifiable under the test conditions. No false negative results were observed.

SYBR Green real-time PCR on seed wash extracts from corn seed. The PCR results for seed wash extracts of 31 Stewart's wilt-infected corn seed lots are shown in Table 2. Twenty-five of the 31 nonconcentrated seed wash samples tested positive (Table 2) with mean $\mathrm{Ct}$ values from 26.47 to 43.83 (45 cycles) (Fig. 3C), indicating a diagnostic sensitivity of $80.6 \%$. Six seed lots did not produce a fluorescent signal $(\mathrm{Ct}=\mathrm{N} / \mathrm{A})$, and one had a weak $\mathrm{Ct}$ value of 43.83 that would likely be considered negative from an unknown sample. The melt curve temperature of $80 \pm 0.5^{\circ} \mathrm{C}$ was consistent across seed lots (Fig. 3D). Agarose gel electrophoresis (data not shown) confirmed the presence of the 256-bp band. When DNA suspensions from concentrated seed washes were used, diagnostic sensitivity improved to $93.5 \%$ ( 29 of 31 seed lots), with mean $\mathrm{Ct}$ values from 19.7 to 43.45 (Table 2). Two seed lots did not produce a fluorescent signal $(\mathrm{Ct}=\mathrm{N} / \mathrm{A})$, and two had weak $\mathrm{Ct}$ values $>40$ that would likely be considered negative if they were unknowns. On average, there was an improvement in sensitivity of about five $\mathrm{Ct}$ cycles between the nonconcentrated seed extracts and the concentrated seed extracts (Table 2).

Seed lots from five ELISA-negative corn accessions tested negative (mean $\mathrm{Ct}=\mathrm{N} / \mathrm{A}$ ) from both concentrated and nonconcentrated seed washes (Table 2). The positive control seed lot AR4 (Table 4) tested positive in all runs. Seed lot AN1 (Table 4) was also included, and its amplicon identity was confirmed by sequencing and comparison with the Genbank sequence for DC283. All 18 seed lots from Hawaii, Puerto Rico, and St. Croix with negative field inspections but positive ELISA results were PCR negative (mean $\mathrm{Ct}=\mathrm{N} / \mathrm{A}$ ) from both concentrated and nonconcentrated seed wash extracts (Table 3).

Conventional PCR. Pure cultures of 7 strains of $P$. stewartii subsp. stewartii and 12 strains of $P$. stewartii subsp. indologenes showed size differences of PCR products from conventional PCR using primers cpsF/cpsR, a 375-bp band from $P$. stewartii subsp. stewartia, and a 193-bp band from P. stewartii subsp. indologenes (Fig. 4A). All 10 P. stewartii subsp. indologenes from corn seed produced the 193-bp amplicon. Bands for 7 of 10 isolates (645-3, 645-14, 649-2, 651-3, 508-3, 655-2B, and 681-4) are shown in Fig. 4A 
Sequencing of the conventional PCR products from $P$. stewartii subsp. indologenes isolates 0696-16, 508-3, 681-4, 649-2, and ATCC 35397 had excellent alignment with $P$. stewartii subsp. indologenes strain LMG2632 (Fig. 5A).

The absence of $P$. stewartii subsp. stewartii from the 18 ELISA false positive seed lots in Table 3 was confirmed by conventional PCR. PCR amplicons from eight Stewart's wilt-positive seed lots and eight false positive seed lots are shown side by side in Fig. 4B. Based on the combination of results from pathogenicity, physiological and biochemical tests, real-time and conventional PCR, and sequencing of cpsAB intergenic sequence, the isolates from corn seed lots of tropical origin were confirmed to be $P$. stewartii subsp. indologenes.

In addition to the nine PCR methods covered in Table 1, we also evaluated PCR methods by Gehring et al. (2014) and Thapa et al. (2012). The recA and galE primer pairs of Gehring et al. (2014) were reported to be subspecies specific and capable of distinguishing the two subspecies by SNPs present at the $3^{\prime}$ end of primers. This study found that the putative $P$. stewartii subsp. stewartii-specific recA primers also amplified 4 of $10 P$. stewartii subsp. indologenes corn seed isolates. Three of the recA-positive isolates $(645-3,645-10$, and 64514) were of Puerto Rican origin, and one (681-4) was from Brazil. Sequencing of recA amplicons indicated that the expected recA SNPs were not always present (data not shown). The P. stewartii subsp. stewartii-specific galE primers of Gehring et al. (2014) were consistent and amplified only $P$. stewartii subsp. stewartii, and the $P$. stewartii subsp. indologenes-specific galE primers amplified only $P$. stewartii subsp. indologenes.

The three primer pairs of Thapa et al. (2012) were not specific for $P$. stewartii subsp. stewartii, because they always amplified one ( $h r p N)$ or two ( $h r p N$ and wtsE) bands from every P. stewartii subsp. indologenes isolate (Supplementary Fig. S1). Nechwatal et al. (2018) reported that the $h r p N$ primers produce a 212-bp amplicon from $P$. stewartii subsp. indologenes (a 12-bp insert) compared with the expected 200-bp amplicon from $P$. stewartii subsp. stewartii. Thus, the lowermost band of $\sim 200$ bp (Thapa et al. 2012) for P. stewartii subsp. indologenes is probably a mixture of two amplicons (the 193-bp amplicon from the cpsF/cpsR primers and a 212-bp $h r p N$ gene product), which cannot be separately resolved on a lowpercentage agarose gel.

\section{Discussion}

The results from the ELISA and nine PCR comparisons added significant new information and supported conclusions from earlier studies (Block et al. 2011; Gehring et al. 2014; Nechwatal et al. 2018; Tambong 2015), which showed that none of the common laboratory assays for $P$. stewartii subsp. stewartii were $100 \%$ reliable. Although all of the methods could readily detect $P$. stewartii subsp. stewartii, they were prone to
A
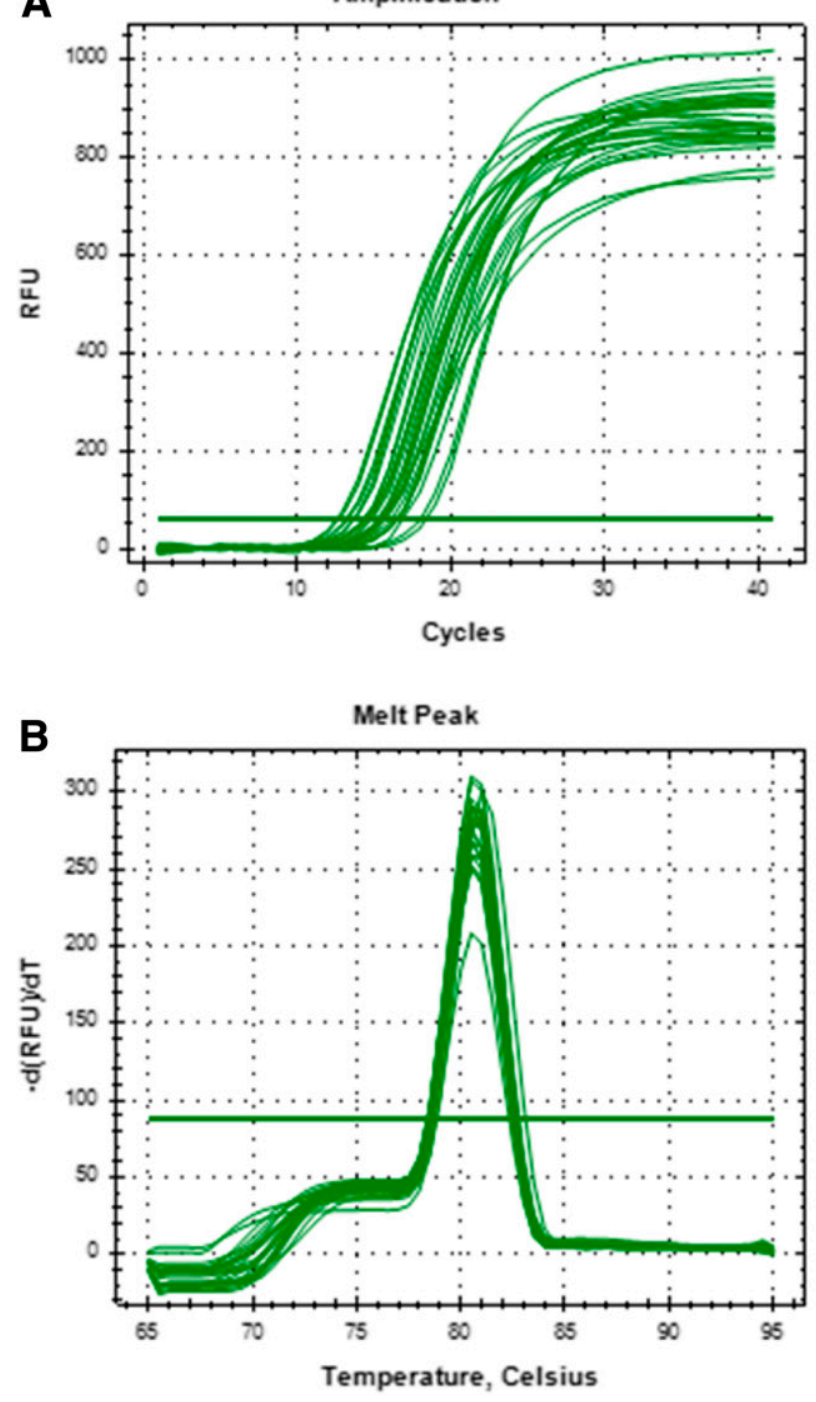
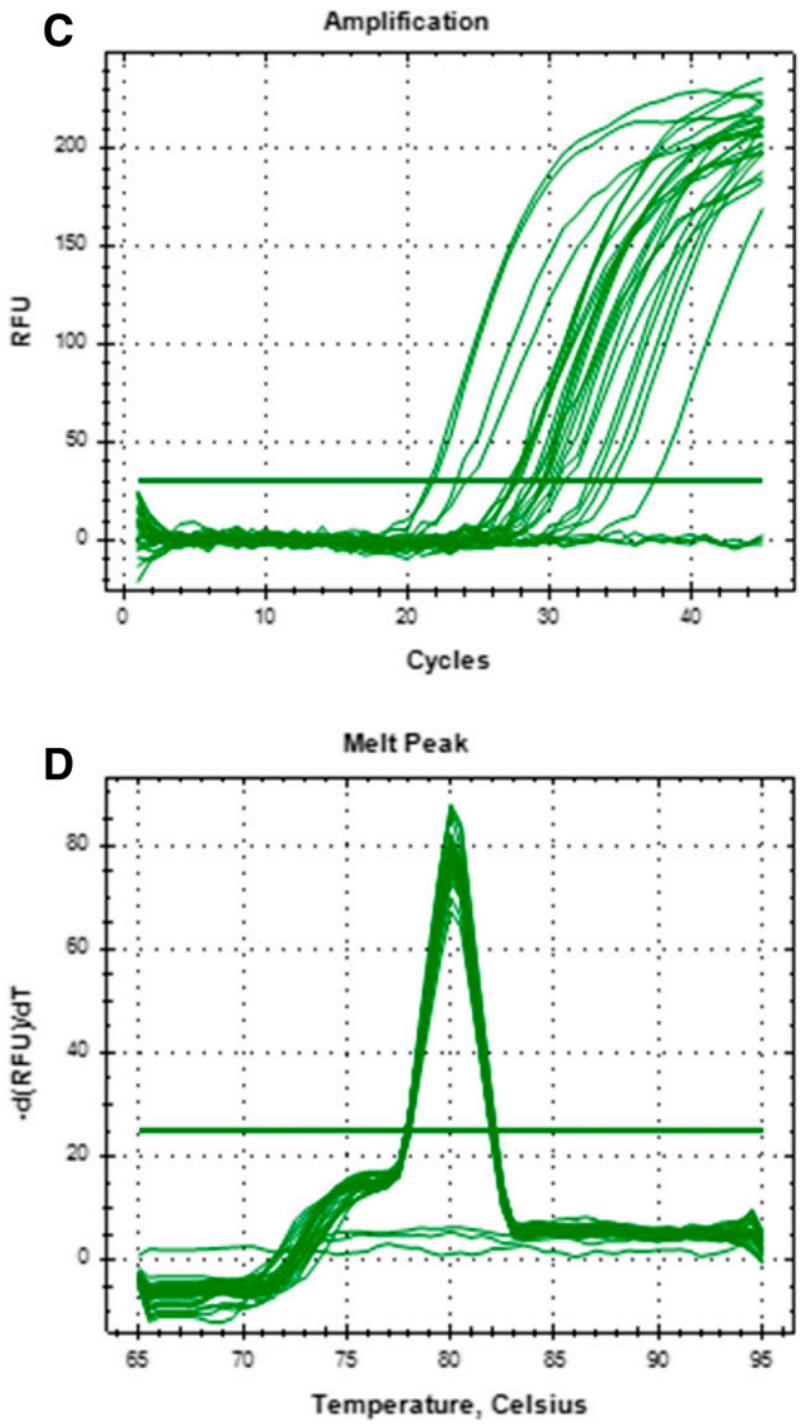

Fig. 3. A and C, Amplification plots and B and D, melt curve profiles of Pantoea stewartii subsp. stewartii-specific amplicons generated in real-time polymerase chain reaction assay with cpsAB2313F and cpsR primer pair using $A$ and $B$, purified genomic DNA or $C$ and D, seed wash from corn seed. Note the melting temperature at $80.5^{\circ} \mathrm{C}$ for genomic DNA and $80^{\circ} \mathrm{C}$ for seed wash. RFU (Y-axis), relative fluorescence units. 
false positives, especially from DNA of $P$. stewartii subsp. indologenes and even from occasional isolates of $P$. ananatis.

There is high DNA sequence homology between the two P. stewartii subspecies at the primer binding sites. Multiple bands or bands of unexpected size were noted from many of the P. stewartii subsp. indologenes isolates, particularly with assays $\mathrm{C}$ and $\mathrm{D}$ that use the same reverse primer (Coplin et al. 2002). None of the off-type bands were sequenced, but they suggest possible sequence variability within the $P$. stewartii subsp. indologenes genome.

$P$. stewartii subsp. indologenes has been reported on several nongrass hosts and may have a more heterogeneous genome than $P$. stewartii subsp. stewartii, which is specialized to corn. The fact that all 7 P. stewartii subsp. indologenes strains obtained from noncorn hosts were ELISA negative but that 9 of the 10 corn seed isolates were ELISA positive also shows a dissimilarity for the corn isolates. The galE primers (Gehring et al. 2014) correctly recognized the respective subspecies in this study, but they depend on single-base pair differences (SNPs) for pathogen identification. The method would require an additional step of sequencing the amplicons to confirm the presence of subspecies-specific galE SNPs, because conventional agarose gel electrophoresis is not sufficient to resolve single-base differences. Moreover, the consistent presence of these SNPs has not yet been shown in any study and would need testing of additional $P$. stewartii subsp. indologenes isolates derived from corn seed. The SYBR Green real-time PCR developed here exploits a 182-bp missing fragment from the cpsAB region of $P$. stewartii subsp. indologenes, a fragment that was present in all $26 P$. stewartii subsp. stewartii isolates tested. Sequencing of amplicons from five $P$. stewartii subsp. indologenes isolates (Fig. 5A) confirmed the absence of the 182-bp fragment in the $\operatorname{cps} A B$ intergenic sequence, which we believe to be a characteristic of $P$. stewartii subsp. indologenes. None of the 36 strains of other Pantoea species and 7 non-Pantoea species showed a cross-reaction.

The analytical sensitivity for purified DNA of $0.1 \mathrm{pg}$ from realtime PCR was higher than the reported sensitivity of $0.5 \mathrm{pg}$ for multiplex PCR (Thapa et al. 2012) and 1 pg for TaqMan real-time PCR (Tambong et al. 2008). The sensitivity of 2.6 CFU per reaction for bacterial cell suspension was similar to the multiplex PCR (1 CFU per reaction) reported by Thapa et al. (2012) and conventional PCR (2.5 CFU per reaction) by Nechwatal et al. (2018) but more sensitive than that of ELISA $\left(2 \times 10^{4} \mathrm{CFU} / \mathrm{g}\right)$ and conventional PCR $(20$ CFU per reaction) by Coplin et al. (2002) or real-time PCR (10 CFU per reaction) by Tambong et al. (2008).

Concentrating the seed wash by centrifugation led to enrichment of target bacterial cells and an increase in the amount of template used in real-time PCR; hence, it resulted in lower $\mathrm{Ct}$ values. The results were not unexpected. However, PCR inhibitors, such as Tween-20 and salts present in the nonwater extraction buffers, could interfere with DNA amplification in centrifuge-only sample preparations. Similar PCR inhibition occurred with ground seed extracts and treated seed. Obviously, extracting and purifying DNA should eliminate problems of PCR inhibition, but the goal was to show that even a quick seed wash and minimal centrifugation were often quite effective in detecting $P$. stewartii subsp. stewartii. Ivanoff (1933) and Rand and Cash (1933) reported the presence of $P$. stewartii bacterial cells in the endosperm and chalazal region (kernel base) of infected kernels. Incubating corn seeds with water as an extraction matrix should result in good recovery of externally located bacterial cells.

This is the first study to validate real-time PCR on seed lots harvested from naturally infected plants using seed washes from whole corn seeds
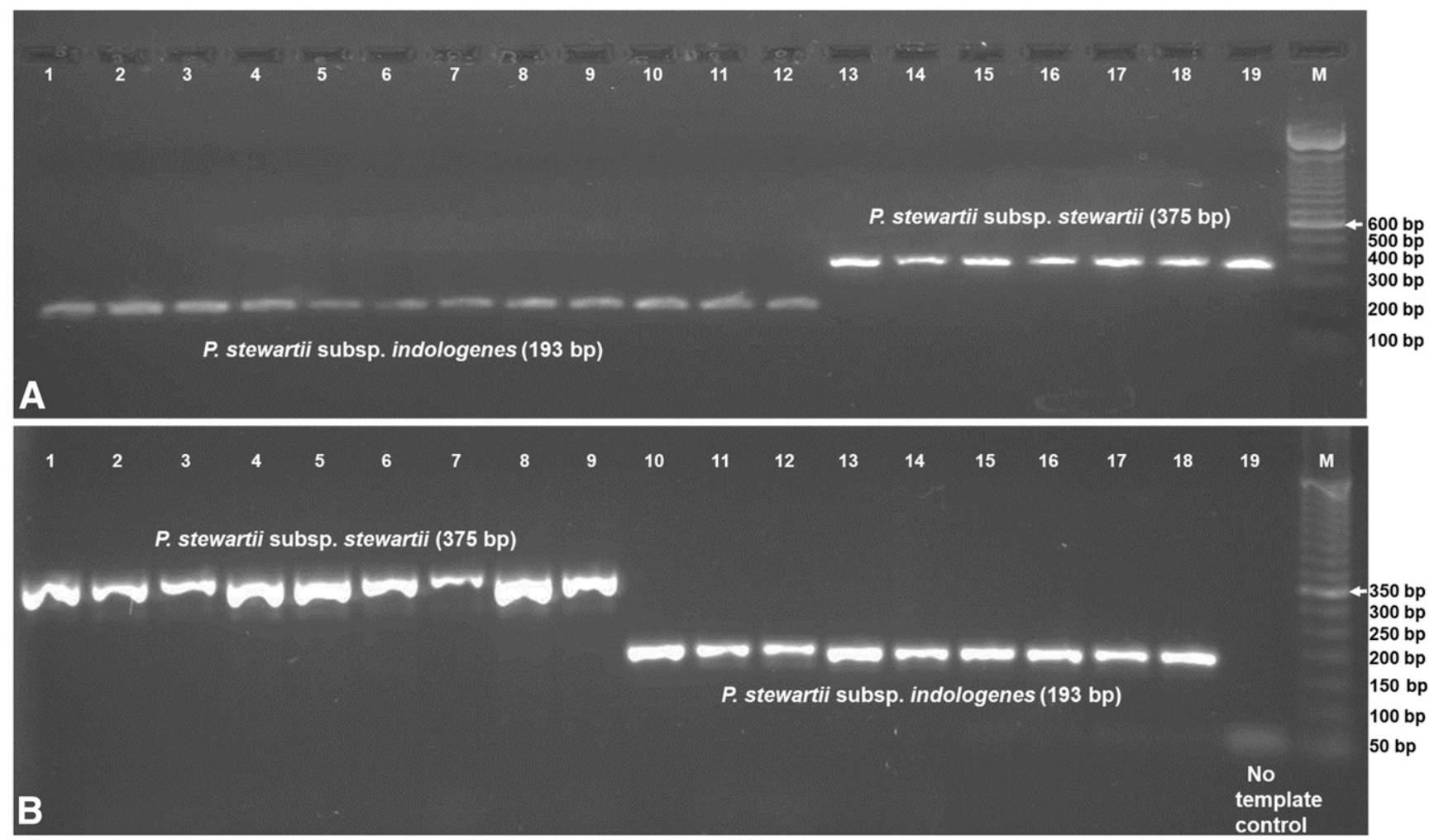

Fig. 4. Conventional polymerase chain reaction (PCR) using cpsF and cpsR primer pair showing PCR product size differentiation for Pantoea stewartii subsp. stewartii and Pantoea stewartii subsp. indologenes. A, PCR was performed with purified genomic DNA from P. stewartii subsp. indologenes strains 0696-21 (lane 1), 0696-19 (lane 2), 645-3 (lane 3), 64514 (lane 4), 649-2 (lane 5), 651-3 (lane 6), 508-3 (lane 7), 655-2B (lane 8), 681-4 (lane 9), ATCC-51785 (lane 10), ATCC-35397 (lane 11), and NRRL B-1061 (lane 12) and P. stewartii subsp. stewartii strains NRRL B-195 (lane 13), DC283 (lane 14), SW1 (lane 15), ES9245 (lane 16), SS104 (lane 17), ATCC-29231 (lane 18), and ATCC-8199 (lane 19). Lane M contains an 100-bp DNA ladder. B, PCR was performed using $5 \mu$ l of nonconcentrated seed wash from Stewart's wilt enzyme-linked immunosorbent assay (ELISA) and real-time PCR-positive (Table 2) corn seed lots PI 587140 (lane 2), PI 595367 (lane 3), PI 658075 (lane 4), PI 658078 (lane 5), PI 658081 (lane 6), PI 180166 (lane 7), Ames 19313 (lane 8), and Ames 27025 (lane 9) and real-time PCR-negative but ELISA-positive (Table 3) corn seed lots A-28655 (lane 11), A-28651 (lane 12), A-28649 (lane 13), A-28645 (lane 14), Ames 32327 15ncei01 (lane 15), PI 503900 15ncei01 (lane 16), PI 59301210 ncei01 (lane 17), and PI 64123912 ncei01 (lane 18 ). Lanes 1 and 10 have amplicons from P. stewartii subsp. stewartii strain DC283 and P. stewartii subsp. indologenes strain ATCC-35397, respectively. Lane 19 is nontemplate sterile water control; lane M contains a 50-bp DNA ladder. 
without requiring pathogen isolation or DNA purification. All but 2 of 31 corn seed lots from naturally infected plants tested positive by SYBR Green real-time PCR. ELISA tests of two 75-kernel subsamples from the two negative seed lots gave a positive absorbance signal from one of two subsamples for each of those two seed lots. Because we used small samples of just 50 seeds, it is possible that an infected kernel was not present in the subsamples. With 50 seeds from a $1 \%$ infected seed lot, there is only a $40 \%$ probability of including 1 infected seed in the sample (SeedCalc software, ISTA, https://www.seedtest.org/en/ home.html). A minimum sample size of 250 seeds would be needed from the $1 \%$ infected seed lot to have a confidence level of $90 \%$ that at least one infected kernel was included.

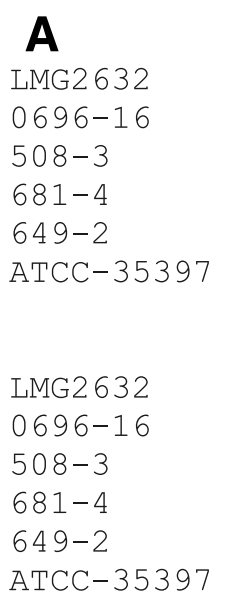

LMG2 632

$0696-16$

$508-3$

$681-4$

$649-2$

ATCC-35397

LMG2 632

$0696-16$

$508-3$

$681-4$

649-2

ATCC-35397
GAAAAAGGTGCCAGCCTCTCTCTGACAGCACATGACAGGGGAGCGGGTTGGTACATTTTT -----AGGTGCCAGCCTCTCTCTGACAGCACACGACAGGGGAGCGGGTTGGTACATTTTT -----AGGTGCCAGCCTCTCTCTGACAGCACACGACAGGGGAGCGGGTTGGTACATTTTT ----AAGGTGCCAGCCTCTCTCTGACAGCACACGACAGGGGAGCGGGTTGGTACATTTTT ----AAGGTGCCAGCCTCTCTCTGACAGCACACGACAGGGGAGCGGGTTGGTACATTTTT ----AAGGTGCCAGCCTCTCTCTGACAGCACACGACAGGGGAGCGGGTTGGTACATTTTT

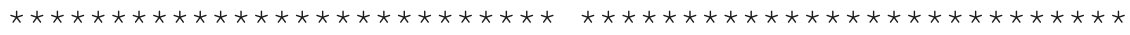

CTAAAAAAAAGCGGTACGGCATTGATAAACAGCCATGTTCTGCTTTGCTTTATTTCTTTC CTAAAAAAAAGCGTACGGCATTGATAAACAGCAATGTTCTGCTTTGCTTTATTTCTTTC CTAAAAAAAAGCGGTACGGCATTGATAAACAGCCATGTTCTGCTTTGCTTTATTTCTTTC CTAAAAAAAAGCGGTACGGCATTGATAAACAGCCATGTTCTGCTTTGCTTTATTTCTTTC CTAAAAAAAAGCGGTACGGCATTGATAAACAGCCATGTTCTGCTTTGCTTTATTTCTTTC CTAAAAAAAAGGGTACGGCATTGATAAACAGCCATGTTCTGCTTTGCTTTATTTCTTTC

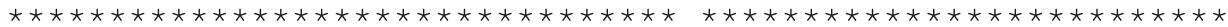

TGGGTAAAGCGCGTGATCGGTAAAAGACAGGAGCTAAGAATAATGAACGACATGTTCAGT

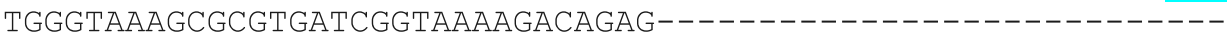
TGGGTAAAGCGCGTGATCGGTAAAAGACAGAG---------------------------

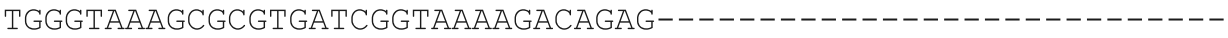
TGGGTAAAGCGCGTGATCGGTAAAAGACAGAGCTA-----------------------TGGGTAAAGCGCGTGATCGGTAAAAGACAGAGCTAAGAAA-----------------

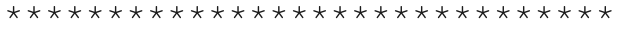

GCCTGAGTCAGGATAGTTTACTTTTTTGAGCGCTTACACAGCGGCGTACTTGCCTCTAT

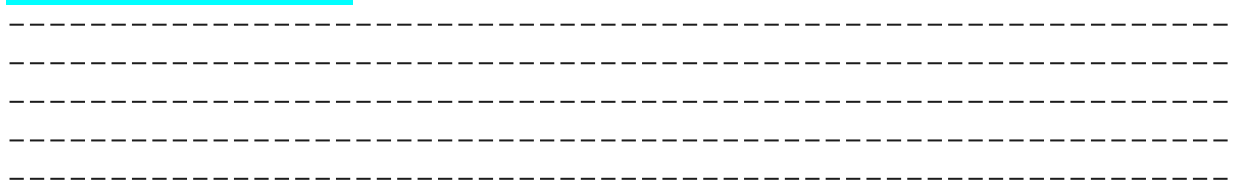

\section{B}

DC283

AN1

DC283

AN1

DC283

AN1

$\mathrm{DC} 283$

AN1

DC283

AN1
GGTAGAAAACGCTGATGCCAGACAGAACACCGTCATACGCAAGCATGTAATGCATTGATT -- AGAAAACGCTGATGCCAGACAGAACACCGTCATACGCAAGCATGTAATGCATTGATT

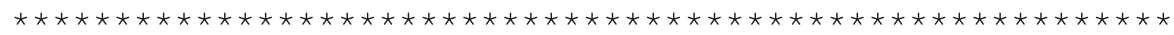

TTATGTTATCTGAAACAACCGTTTTCATAGTACCACAGCATAAAATCCATTTATTCAACA TTATGTTATCTGAAACAACCGTTTTCATAGTACCACAGCATAAAATCCATTTATTCAACA

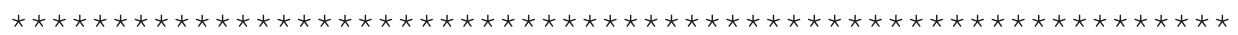
AAGCCAAAAAAAGCGGTACGGCATTGATAAACAGCAATGTTCTGCTTTGCTTTATTTATT AAGCCAAAAAAAGCGGTACGGCATTGATAAACAGCAATGTTCTGCTTTGCTTTATTTATT

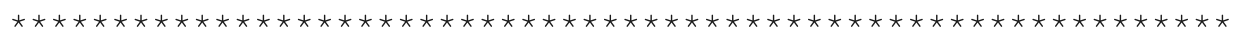
TCTGGGTAAAGCGCGTGATCGGTAAAAGACAGGAGCTAAGAATAATGAACGACATGTTCA TCTGGGTAAAGCGCGTGATCGGTAAAAGACAGAG-----------------------

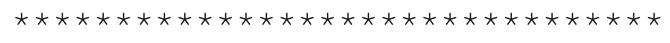

Fig. 5. Amplicon sequences generated from A, conventional polymerase chain reaction (PCR) using purified genomic DNA of Pantoea stewartii subsp. indologenes strains 069616, ATCC-35397, 508-3, 681-4, and 649-2 and B, real-time PCR of seed wash from seed lot AN1. Sequences were aligned with reference sequences of $P$. stewartii subsp. indologenes strain LMG2632 (GenBank accession number JPK001000031) and Pantoea stewartii subsp. stewartii strain DC283 (GenBank accession number CP017581) using Clustal Omega. The primer binding site for the cpsR primer used in the sequencing reaction is highlighted. *Identical sequence.

Plant Disease / July $2019 \quad 1485$ 
Other more complex methods have been developed for $P$. stewartii subspecies differentiation. Wu et al. (2007) used a proteomics-based approach to identify differences in protein expression profiles of the two subspecies. A genotyping method developed by Xu et al. (2010) involves evaluation of a complex DNA fingerprint for subspecies differentiation. Both methods are time consuming and require expensive equipment or specialized expertise, and they do not seem to be practical for routine seed health testing. The multigene oligonucleotide array method described by Tambong (2015) involves multiplex PCR reactions, digoxigenin labeling of amplicons, and probe hybridization, and it does not seem to be a simple, convenient, or costeffective option.

The P. stewartii ELISA developed by Lamka et al. (1991) is still a very effective test and commonly used for phytosanitary seed certification. The SYBR Green real-time PCR method developed here could serve as a standalone method, or it could be used in combination with ELISA. Corn seed lots that test positive by ELISA can be confirmed for the presence or absence of $P$. stewartii subsp. stewartii by real-time PCR, conventional PCR, or a combination of both methods. To our knowledge, this is the first study to show PCR methods that can detect $P$. stewartii subsp. stewartii directly from the seed wash and readily distinguish it from the closely related $P$. stewartii subsp. indologenes.

\section{Acknowledgments}

We thank Mark Millard (U.S. Department of Agriculture-Agricultural Research Service North Central Regional Plant Introduction Station, Ames, IA) for providing corn seed for use in the study. We acknowledge the contribution of Lisa Shepherd (formerly of Iowa State University Seed Science Center) to this work.

\section{Literature Cited}

Blakemore, E. J. A., Law, J. R., and Reeves, J. C. 1999. PCR identification of Erwinia stewartii and its comparison with two other methods. Seed Sci. Technol. 27:385-396.

Block, C. C., Hill, J. H., and McGee, D. C. 1998. Seed transmission of Pantoea stewartii in field and sweet corn. Plant Dis. 82:775-780.

Block, C. C., Shepherd, L. M., and Munkvold, G. P. 2011. Comparison of nine PCR primer sets designed to detect Pantoea stewartii subsp. stewartii in maize. Phytopathology 101:S16.

CABI. 2018. Pantoea stewartii (bacterial wilt of maize). in: Crop Protection Compendium (Online database: https://www.cabi.org/cpc/). CAB International, Wallingford, United Kingdom.

Cook, K. A., Weinzier, R. A., Pataky, J. K., Esker, P. D., and Nutter, J. F. W. 2005. Population densities of corn flea beetle (Coleoptera: Chrysomelidae) and incidence of Stewart's wilt in sweet corn. J. Econ. Entomol. 98:673-682.

Coplin, D. L., and Majerczak, D. R. 1990. Extracellular polysaccharide genes in Erwinia stewartii: Directed mutagenesis and complementation analysis. Mol. Plant-Microbe Interact. 3:286-292.

Coplin, D. L., Majerczak, D. R., Zhang, Y., Kim, W. S., Jock, S., and Geider, K. 2002. Identification of Pantoea stewartii subsp. stewartii by PCR and strain differentiation by PFGE. Plant Dis. 86:304-311.

Dye, D. W. 1963. The taxonomic position of Xanthomonas stewartii (Erw. Smith 1914) Dowson 1939. N. Z. J. Sci. 6:495-506.

Elliott, C., and Poos, F. W. 1934. Overwintering of Aplanobacter stewartii. Science 80:289-290.

Elliott, C., and Poos, F. W. 1940. Seasonal development, insect vectors, and host range of bacterial wilt of sweet corn. J. Agric. Res. 60:645-686.

EPPO. 2016. PM 7/60 (2) Pantoea stewartii subsp. stewartii. Bull. OEPP/EPPO Bull. 46:226-236.

Gehring, I., Wensing, A., Gernold, M., Wiedemann, W., Coplin, D. L., and Geider, K. 2014. Molecular differentiation of Pantoea stewartii subsp. indologenes from subspecies stewartii and identification of new isolates from maize seeds. J. Appl. Microbiol. 116:1553-1562.

Ivanoff, S. S. 1933. Stewart's wilt disease of corn with emphasis on the life history of Phytomonas stewartii in relation to pathogenesis. J. Agric. Res. 47:749-770.
Jardine, D. J., and Claflin, L. E. 2016. Stewart's bacterial wilt. Pages 7-10 in: Compendium of Corn Diseases. G. P. Munkvold and D. G. White, eds. The American Phytopathological Society, St. Paul, MN.

Johnston-Monje, D., and Raizada, M. N. 2011. Conservation and diversity of seed associated endophytes in Zea across boundaries of evolution, ethnography and ecology. PLoS One 6:e20396.

Lamka, G. L., Hill, J. H., McGee, D. C., and Braun, E. J. 1991. Development of an immunosorbent assay for seedborne Erwinia stewartii in corn seeds. Phytopathology 81:839-846.

Lane, D. J. 1991. 16S/23S rRNA sequencing. Pages 115-176 in: Nucleic Acid Techniques in Bacterial Systematics. E. Stackebrandt and M. Goodfellow, eds. John Wiley \& Sons, Inc., New York, NY.

Liu, Y., Zuo, S., Zou, Y., Wang, J., and Song, W. 2012. Investigation on diversity and population succession dynamics of indigenous bacteria of the maize spermosphere. World J. Microbiol. Biotechnol. 28:391-396.

Mergaert, J., Verdonck, L., and Kersters, K. 1993. Transfer of Erwinia ananas (synonym Erwinia uredovora) and Erwinia stewartii to the genus Pantoea emend. as Pantoea ananas (Serrano 1928) comb. nov. and Pantoea stewartii (Smith 1898) comb. nov., respectively, and description of Pantoea stewartii subsp. indologenes subsp. nov. Int. J. Syst. Bacteriol. 43:162-173.

Michener, P. M., Pataky, J. K., and White, D. G. 2002. Rates of transmitting Erwinia stewartii from seed to seedlings of a sweet corn hybrid susceptible to Stewart's wilt. Plant Dis. 86:1031-1035.

Nechwatal, J., Friedrich-Zorn, M., Theil, S., Gebauer, P., and Wensing, A. 2018. Validation of a specific PCR screening test for Pantoea stewartii subsp. stewartii in maize (Zea mays) samples. Bull. OEPP/EPPO Bull. 48:78-85.

Nübel, U., Engelen, B., Felske, A., Snaidr, J., Wieshuber, A., Amann, R. I., Ludwig, W., and Backhaus, H. 1996. Sequence heterogeneities of genes encoding 16S rRNAs in Paenibacillus polymyxa detected by temperature gradient gel electrophoresis. J. Bacteriol. 178:5636-5643.

Rand, F. V., and Cash, L. C. 1933. Bacterial wilt of corn. USDA Technical Bulletin 362.

Stewart, F. C. 1897. A bacterial disease of sweet corn. N. Y. Agric. Exp. Stn. Bull 130:422-439.

Stumpf, S., Kvitko, B., Gitatitis, R., and Dutta, B. 2018. Isolation and characterization of novel Pantoea stewartii subsp. indologenes strains exhibiting center rot in onion. Plant Dis. 102:727-733.

Suparyono, Pataky, J. K. 1989. Influence of host resistance and growth stage at the time of inoculation on Stewart's wilt and Goss's wilt development and sweet corn hybrid yield. Plant Dis. 73:339-345.

Tambong, J. T. 2015. Specific identification and detection of Pantoea stewartii subsp. stewartii using a membrane-based multi-gene oligonucleotide array. Can. J. Plant Pathol. 37:414-426.

Tambong, J. T., Mwange, K. N., Bergeron, M., Ding, T., Mandy, F., Reid, L. M. and Zhu, X. 2008. Rapid detection and identification of the bacterium Pantoea stewartii in maize by Taqman real-time PCR assay targeting the cpsD gene. J. Appl. Microbiol. 104:1525-1537.

Thapa, S. P., Park, D. H., Wilson, C., Hur, J. H., and Lim, C. K. 2012. Multiplex PCR assay for the detection of Pantoea stewartii subsp. stewartii using species-specific genetic markers. Australas. Plant Pathol. 41:559-564.

Uematsu, H., Inoue, Y., and Ohto, Y. 2015. Detection of Pantoea stewartii from sweet corn leaves by loop-mediated isothermal amplification (LAMP). J. Gen. Plant Pathol. 81:173-179.

Wang, X. 2011. Characterization of exopolysaccharide biosynthetic genes, wceF, wceJ, wzx1, of Pantoea stewartii subsp. stewartii and their corresponding homologues of Erwinia amylovora. Doctoral dissertation. University of Connecticut, Storrs, CT.

Wensing, A., Zimmermann, S., and Geider, K. 2010. Identification of the corn pathogen Pantoea stewartii by mass spectrometry of whole-cell extracts and its detection with novel PCR primers. Appl. Environ. Microbiol. 76: 6248-6256.

Wilson, W. J., Wiedmann, M., Dillard, H. R., and Batt, C. A. 1994. Identification of Erwinia stewartii by a ligase chain reaction assay. Appl. Environ. Microbiol. 60:278-284.

Wu, Q., Jiang, Z., Liao, J., Chen, Z., Li, H., Mei, M., and Zhang, L. H. 2007. Identification of genetic markers to distinguish the virulent and avirulent subspecies of Pantoea stewartii by comparative proteomics and genetic analysis. Appl. Microbiol. Biotechnol. 74:186-193.

Xu, R., Chen, Q., Djama, Z. R., and Tambong, J. T. 2010. Miniprimer PCR assay targeting multiple genes: A new rapid and reliable tool for genotyping Pantoea stewartii subsp. stewartii. Lett. Appl. Microbiol. 50:216-222. 